\title{
Molecular structure and vibrational spectra of methyl glycolate and methyl $\alpha$-hydroxy isobutyrate ${ }^{\text {is }}$
}

\author{
S. Jarmelo, R. Fausto* \\ Departamento de Química, Universidade de Coimbra, P-3049 Coimbra, Portugal
}

Received 10 March 1999; accepted 6 April 1999

\begin{abstract}
Conformational isomerism in isolated and liquid methyl glycolate and methyl $\alpha$-hydroxy isobutyrate was investigated by a concerted molecular orbital and vibrational spectroscopic approach (infrared and Raman). The molecular structures, relative energies, dipole moments and vibrational spectra of the various possible conformers of the studied compound were calculated, using the extended 6-31G* basis set at the HF-SCF ab initio level of theory. The theoretical results were then used to interpret infrared and Raman data obtained under different experimental conditions. It was found that both in the liquid and gaseous phase the studied molecules exist in two experimentally observed conformational states, the $\mathrm{C}_{\mathrm{s}}$ point group $S y n-s y n$ conformer (Ss), which exhibits an intramolecular $\mathrm{OH} \cdots \mathrm{O}=$ hydrogen bond, being the most stable form. As expected, the relative populations of the second more stable conformers increase in the liquid phase, since intermolecular interactions tend to reduce the importance of the intramolecular H-bonding that is the main stabilizing factor of the Ss forms. (C) 1999 Elsevier Science B.V. All rights reserved.
\end{abstract}

Keywords: Methyl glycolate; Methyl $\alpha$-hydroxy isobutyrate; Molecular structure; Conformational isomerism; Pure liquid infrared spectra; Matrix-isolation spectra; 6-31G* ab initio calculations; Intra- and intermolecular hydrogen bonding

\section{Introduction}

$\alpha$-Hydroxy carboxylic compounds have important medical and pharmaceutical applications, which justify the recent growing interest for this kind of compound [1-4]. Besides their well known use in the dermatology and cosmetics industry [1,2], these substances are also currently used as inhibitors of harmful oxidation biochemical processes [3], while

\footnotetext{
${ }^{2}$ In honour of Professor Peter Klæboe on the occasion of his 70th birthday.

* Corresponding author. Tel.: + 351-39-852080; fax: + 35139-827703.

E-mail address: rfausto@gemini.ci.uc.pt (R. Fausto)
}

important research is presently going on in order to develop new materials based on biodegradable polymers derived from $\alpha$-hydroxy carboxylic compounds that can be used for reconstruction of biological tissues and in organ transplantation [5]. In addition, these molecules also play an important role as precursors of polymeric materials currently used for different applications (e.g. polyester polymers derived from methyl glycolate [6]).

From a more fundamental perspective, $\alpha$ hydroxy carboxylic compounds also appear as very attractive and challenging systems, since the close proximity of the $\alpha$-hydroxy and carboxylic groups are expected to give rise to a series of different possible intramolecular interactions in the isolated molecule and lead to a variety of intermolecular 
interactions in the condensed phases. Among these, intra- and intermolecular hydrogen bonding certainly play a fundamental role.

Being the simplest member of this family of molecules, glycolic acid is by far the most studied $\alpha$-hydroxy acid, both experimentally and theoretically [7-15]. However, its methyl ester has not been paid much attention. In fact, to the best of our knowledge, only the 1983 spectroscopic study of Hollenstein et al. has been undertaken on methyl glycolate [16]. In that study, the infrared spectra of methyl glycolate in the gaseous phase and isolated in an Argon matrix were investigated in order to extend a previously obtained empirical valence force field derived for a series of carbonyl containing molecules (e.g. formic and acetic acids and their methyl esters, pyruvic acid, acetone [17]) to this molecule and glycolic acid, and test a different approach for the concept of valence force field transferability based on topological properties of the molecular structures. Several isotopic modifications of methyl glycolate were used and an assignment of the fundamental vibrations of the dominant conformational state was proposed [16]. However, despite being mentioned very briefly, the presence in the sample of less stable conformers was not examined and no studies were undertaken on the pure liquid (where higher energy conformational states are expected to contribute in larger extent to the observed spectra than in the low temperature matrix sample). Further, in the absence of data concerning the molecular geometry of the studied compound, Hollenstein et al. used in their vibrational calculations, geometric parameters transferred from simpler molecules (glycolic acid, methyl acetate and methyl formate [16]), and it is well known that such a procedure may occasionally lead to relevant deviations from the ideal geometries. To conclude, it can be stated that in spite of the great contribution to the vibrational study of methyl glycolate given by Hollenstein et al., there are important questions still open to spectroscopic investigation, while a detailed structural study on this compound appears to be essential to provide the necessary basis for interpreting the experimental data.

Substitution of the methylene hydrogens of methyl glycolate by methyl groups does not change the molecular symmetry and is not expected to lead to dramatic changes in the molecular properties. Indeed, despite the larger volume of the $\alpha$-substituent methyl groups must certainly affect molecular properties to some extent, the prevalent interactions between the $\alpha$-hydroxy and carboxylic groups are not expected to be strongly affected by this substitution. Then, the simultaneous study of methyl glycolate and $\alpha$-hydroxy isobutyrate may present some advantages to attain a deeper understanding of both the structural and vibrational properties of these two molecules.

In this study, the structures, conformational properties and vibrational spectra of methyl glycolate and $\alpha$-hydroxy isobutyrate were studied by a multidisciplinary approach using conventional infrared and Raman spectroscopy in the liquid phase, matrix isolation infrared spectroscopy and quantum chemical calculations. The most stable conformers of the two studied molecules were structurally characterized and their vibrational spectra interpreted. In addition, the relevance of intra- and intermolecular hydrogen bonding in determining the relative populations of the experimentally observed conformers in the different experimental conditions considered was evaluated.

\section{Experimental}

Both methyl glycolate and methyl $\alpha$-hydroxy isobutyrate obtained were commercially spectroscopic grade and used without any additional purification.

Infrared spectra were obtained using a Mattson Infinity Series Fourier transform spectrometer equipped with a germanium $/ \mathrm{KBr}$ beam splitter and a deuterated triglycine sulphide (DTGS) detector fitted with $\mathrm{KBr}$ windows. For liquid phase studies, data collection was performed with $2 \mathrm{~cm}^{-1}$ spectral resolution using a specially designed dismountable transmission variable temperature cell with $\mathrm{AgCl}$ windows, linked to a T48 (Red Lion Controls) temperature controller. Infrared studies undertaken in the matrices used a spectral resolution of $1 \mathrm{~cm}^{-1}$.

Argon with $99.99990 \%$ purity was supplied by Air Liquids. All matrices were prepared in a conventional way by deposition of the gaseous mixture (pre-mixed temperature: $298 \mathrm{~K}$ ) on a $\mathrm{KBr}$ window, cooled using an APD Cryogenics Displex DE202 closed-cycle 
Helium refrigerator connected to a high efficiency vacuum system whose main component is an Alcatel PTR5001 turbomolecular pump. The deposition temperature, measured at the window with a Pt100 sensor and a Scientific Instruments digital temperature controller (model 9650), was $17 \mathrm{~K}$. The matrix:solute ratios were ca. 1000 and the rates of the matrix gas flow ca. $5.0 \times 10^{-3} \mathrm{~mol} \mathrm{~h}^{-1}$.

Raman spectra were obtained using a SPEX 1403 double monochromator spectrometer (focal distance $0.85 \mathrm{~m}$, aperture $f / 7.8$ ), equipped with holographic gratings with 1800 grooves $/ \mathrm{mm}^{-1}$ (ref. 1800-1SHD). The $514.5 \mathrm{~nm}$ argon laser (Spectra-Physics, model 164-05) line, adjusted to provide $220 \mathrm{~mW}$ power at the sample, was used as excitation radiation. Detection was effected using a thermoelectrically cooled Hamamatsu R928 photomultiplier. Spectra were recorded using increments of $2 \mathrm{~cm}^{-1}$ and integration times of $1 \mathrm{~s}$.

The ab initio molecular orbital calculations were performed using the $6-31 \mathrm{G}^{*}$ basis set [18] with the GAUSSIAN 94 program package [19] running on a DEC ALPHA 7000 computer. Molecular geometries were fully optimized by the force gradient method using Berny's algorithm [20] and the standard convergence criteria for geometry optimization. The force constants (symmetry internal coordinates) to be used in the normal coordinate analysis were obtained from the ab initio cartesian harmonic force constants using the program TRANSFORMER [21]. This program was also used to prepare the input data for the normal coordinate analysis programs used in this study (BUILD-G and VIBRAT [22]). The calculated force fields were then scaled down by using a simple linear regression $\left(\nu_{\text {scaled }}=0.895 \times \nu_{\text {ab-initio }}-3.00\right)$ in order to adjust the calculated to the experimental frequencies. Non-observed bands (or bands doubtfully ascribable using only a pure empirical approach) were then calculated from the corresponding force fields by interpolation using the straight lines obtained previously. While being very simple, this scaling procedure preserves the potential energy distributions (PEDs) as they emerge from the ab initio calculations, thus having an important advantage over the more elaborate force field scaling procedures that use more than one scale factor and usually give rise to important PEDs distortions from the ab initio calculated values.

\section{Results and discussion}

\subsection{Structures and conformer relative energies}

\subsubsection{Methyl glycolate}

Table 1 and Fig. 1 summarize the structural results obtained for methyl glycolate. This molecule has three axes for internal rotation that may lead to conformational isomerism, corresponding to rotation about the carboxylic and hydroxy $\mathrm{C}-\mathrm{O}$ bonds and $\mathrm{C}-$ C. As usually found in methyl carboxylic esters [2325], internal rotation about the methyl $\mathrm{O}-\mathrm{C}$ bond does not lead to different conformers, the methyl group assuming a staggered conformation relatively to the carboxylic fragment with a $\mathrm{C}-\mathrm{H}$ bond occupying an anti periplanar position with respect to the carboxylic $\mathrm{C}-\mathrm{O}$ bond (see Fig. 1).

The preferred conformation of the methyl ester group about the central $\mathrm{C}-\mathrm{O}$ bond in carboxylic esters has been studied in detail previously, and it was shown that, unless specific intramolecular interactions (or ring constraints) are operating in a given molecule, it corresponds to the s-cis conformation, where the $\mathrm{O}=\mathrm{C}-\mathrm{O}-\mathrm{C}$ dihedral angle is equal to $0^{\circ}$ [23-28]. In general, a second stable conformation is also observed (the s-trans form, where $\mathrm{O}=\mathrm{C}-$ $\mathrm{O}-\mathrm{C}$ is $180^{\circ}$ ), but this corresponds to a high energy form having an energy ca. $20 \mathrm{~kJ} \mathrm{~mol}^{-1}$ higher than the $\mathrm{s}$-cis form and an energy barrier separating the two forms usually larger than $40 \mathrm{~kJ} \mathrm{~mol}^{-1}$ [23-28]. Taking into account the large energy difference between the s-cis and s-trans configurations of the $\mathrm{O}=\mathrm{C}-\mathrm{O}-\mathrm{C}$ axis, in this study the conformational search in the potential energy surface of methyl glycolate has been restricted to the s-cis $(\mathrm{C}-\mathrm{O})$ region (the same procedure was also adopted in the case of $\alpha$ hydroxy isobutyrate).

The ab initio $6-31 G^{*}$ calculations predict the existence of six different s-cis $(\mathrm{C}-\mathrm{O})$ conformers of methyl glycolate (see Fig. 1), the conformational ground state corresponding to the Syn-syn (Ss) conformer (point group $\mathrm{C}_{\mathrm{s}}$ ), where both the $\mathrm{H}-\mathrm{O}-$ $\mathrm{C}-\mathrm{C}$ and $\mathrm{O}-\mathrm{C}-\mathrm{C}=\mathrm{O}$ dihedral angles are equal to $0^{\circ}$. This conformer is stabilized by a relatively strong intramolecular hydrogen bond involving the $\alpha$ hydroxy group and the carbonylic oxygen $(\mathrm{OH} \cdots \mathrm{O}=)$, and has an energy of $9.0 \mathrm{~kJ} \mathrm{~mol}^{-1}$ lower than the second more stable form, the doubly 
Table 1

6-31G* calculated molecular structures, relative energies and dipole moments for the studied conformers of methyl glycolate (bond lengths in $\mathrm{pm}$, angles in degrees, relative energies in $\mathrm{kJ} \mathrm{mol}^{-1}$, dipole moments in Debyes $\left(1\right.$ Debye $\left.=3.33564 \times 10^{-30} \mathrm{C} \mathrm{m}\right)$. See Fig. 1 for atom numbering)

\begin{tabular}{|c|c|c|c|c|c|c|}
\hline \multirow[t]{2}{*}{ Parameter } & \multicolumn{6}{|l|}{ Conformer } \\
\hline & Ss & Gsk & $\mathbf{G a}$ & $\mathbf{S a}$ & As & Aa \\
\hline $\mathrm{C}=\mathrm{O}$ & 119.0 & 118.7 & 118.8 & 118.6 & 118.2 & 119.0 \\
\hline $\mathrm{C}-\mathrm{C}$ & 151.2 & 151.6 & 151.7 & 151.6 & 151.2 & 151.4 \\
\hline $\mathrm{C}-\mathrm{O}$ & 131.6 & 132.4 & 132.1 & 132.4 & 132.7 & 131.1 \\
\hline $\mathrm{O}-\mathrm{C}\left(\mathrm{H}_{3}\right)$ & 142.0 & 142.0 & 142.0 & 142.1 & 141.7 & 141.7 \\
\hline $\mathrm{C}-\mathrm{O}(\mathrm{H})$ & 138.6 & 138.9 & 138.8 & 139.1 & 138.8 & 139.1 \\
\hline $\mathrm{OH}$ & 95.1 & 94.8 & 94.7 & 94.7 & 94.7 & 94.7 \\
\hline $\mathrm{C}-\mathrm{H}_{(8)}$ & 108.6 & 107.9 & 108.4 & 108.5 & 108.7 & 108.7 \\
\hline $\mathrm{C}-\mathrm{H}_{(9)}$ & 108.6 & 108.9 & 108.4 & 108.5 & 108.7 & 108.7 \\
\hline $\mathrm{C}-\mathrm{H}_{(10)}$ & 108.0 & 108.0 & 108.0 & 108.0 & 108.0 & 108.0 \\
\hline $\mathrm{C}-\mathrm{H}_{(11)}$ & 107.8 & 107.8 & 107.8 & 107.8 & 107.9 & 107.8 \\
\hline $\mathrm{C}-\mathrm{H}_{(12)}$ & 108.0 & 108.0 & 108.0 & 108.0 & 108.0 & 108.0 \\
\hline $\mathrm{C}-\mathrm{C}=\mathrm{O}$ & 123.1 & 123.8 & 122.7 & 123.1 & 126.4 & 120.9 \\
\hline $\mathrm{O}=\mathrm{C}-\mathrm{O}$ & 124.7 & 124.1 & 124.2 & 124.1 & 124.3 & 124.5 \\
\hline $\mathrm{C}-\mathrm{O}-\mathrm{C}$ & 117.2 & 117.1 & 117.0 & 117.2 & 116.8 & 116.8 \\
\hline $\mathrm{O}-\mathrm{C}-\mathrm{C}$ & 111.3 & 114.3 & 115.3 & 115.3 & 109.5 & 112.1 \\
\hline $\mathrm{H}-\mathrm{O}-\mathrm{C}$ & 108.6 & 109.5 & 110.0 & 109.9 & 109.4 & 109.2 \\
\hline $\mathrm{C}-\mathrm{C}-\mathrm{H}_{(8)}$ & 108.2 & 107.8 & 106.9 & 106.7 & 107.5 & 106.3 \\
\hline $\mathrm{C}-\mathrm{C}-\mathrm{H}_{(9)}$ & 108.2 & 106.7 & 106.9 & 106.7 & 107.5 & 106.3 \\
\hline $\mathrm{O}-\mathrm{C}-\mathrm{H}_{(10)}$ & 110.3 & 110.3 & 110.3 & 110.2 & 110.5 & 110.5 \\
\hline $\mathrm{O}-\mathrm{C}-\mathrm{H}_{(11)}$ & 105.8 & 105.9 & 105.8 & 105.9 & 105.9 & 105.7 \\
\hline $\mathrm{O}-\mathrm{C}-\mathrm{H}_{(12)}$ & 110.3 & 110.3 & 110.3 & 110.2 & 110.5 & 110.5 \\
\hline $\mathrm{C}-\mathrm{C}(=\mathrm{O})-\mathrm{O}$ & 180.0 & -176.7 & -177.3 & 180.0 & 180.0 & 180.0 \\
\hline $\mathrm{O}=\mathrm{C}-\mathrm{O}-\mathrm{C}$ & 0.0 & -1.5 & -1.3 & 0.0 & 0.0 & 0.0 \\
\hline $\mathrm{O}=\mathrm{C}-\mathrm{C}-\mathrm{O}$ & 0.0 & 155.0 & 176.8 & 180.0 & 0.0 & 180.0 \\
\hline $\mathrm{C}-\mathrm{C}-\mathrm{O}-\mathrm{H}$ & 0.0 & 48.5 & 40.2 & 0.0 & 180.0 & 180.0 \\
\hline $\mathrm{O}=\mathrm{C}-\mathrm{C}-\mathrm{H}_{(8)}$ & 122.0 & 34.8 & 57.3 & 57.2 & 122.4 & 57.1 \\
\hline $\mathrm{O}=\mathrm{C}-\mathrm{C}-\mathrm{H}_{(9)}$ & -122.0 & -80.7 & -57.3 & -57.2 & -122.4 & -57.1 \\
\hline $\mathrm{C}-\mathrm{O}-\mathrm{C}-\mathrm{H}_{(10)}$ & -60.6 & -60.5 & -60.5 & -60.5 & -60.5 & -60.5 \\
\hline $\mathrm{C}-\mathrm{O}-\mathrm{C}-\mathrm{H}_{(11)}$ & 60.6 & 60.5 & 60.5 & 60.5 & 60.5 & 60.5 \\
\hline $\mathrm{C}-\mathrm{O}-\mathrm{C}-\mathrm{H}_{(12)}$ & 180.0 & 180.0 & 180.0 & 180.0 & 180.0 & 180.0 \\
\hline$\Delta E^{\mathrm{a}}$ & - & 9.0 & 11.0 & 11.9 & 21.0 & 22.2 \\
\hline$|\mu|$ & 3.062 & 2.620 & 2.336 & 2.485 & 3.510 & 1.520 \\
\hline
\end{tabular}

${ }^{\text {a }}$ Relative energies to the most stable form. Calculated total energy for the Ss conformer is $-897091.2 \mathrm{~kJ} \mathrm{~mol}^{-1}$.

degenerated by symmetry Gauche-skew conformer (Gsk, point group: $\mathrm{C}_{1}$ ) exhibiting $\mathrm{H}-\mathrm{O}-\mathrm{C}-\mathrm{C}$ and $\mathrm{O}-\mathrm{C}-\mathrm{C}=\mathrm{O}$ dihedrals of 48.5 and $155.0^{\circ}$, respectively. All the remaining conformers ( $\mathbf{G a}, \mathbf{S a}, \mathbf{A s}$ and $\mathbf{A a}$; see Fig. 1 and Table 1) are predicted to have energies higher than that of the most stable form by more than $11 \mathrm{~kJ} \mathrm{~mol}^{-1}$. Thus, assuming a Boltzmann distribution, the two lower conformational states of methyl glycolate represent ca. 97\% of the conformational population at room temperature (Ss: 92\%; Gsk:
$5 \%$ ). It is worth mentioning that these two conformers are similar to the two most stable conformers of monomeric glycolic acid and that their relative energies are also similar to those found for this molecule [15].

As it could be anticipated, the $\mathrm{OH} \cdots \mathrm{O}=$ intramolecular hydrogen bonding present in the Ss conformer leads to a longer $\mathrm{OH}$ bond in this form than in the other conformers, and also to a more positively charged hydroxylic hydrogen (charge on $\mathrm{H}_{(7)}$ is 
<smiles>[1H]C(=O)OC</smiles>

Syn-syn (Ss)

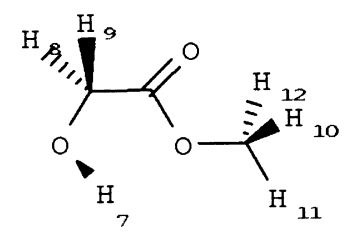

Gauche-anti (Ga)

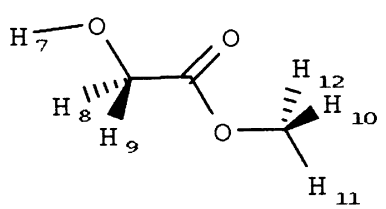

Anti-syn (As)

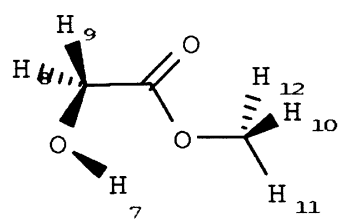

Gauche-skew (Gsk)

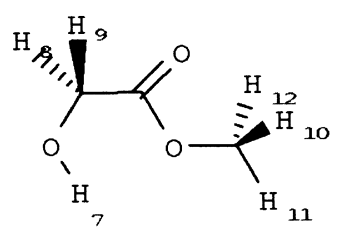

Syn-anti (Sa)

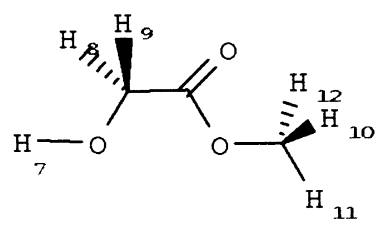

Anti-anti (Aa)

Fig. 1. Conformers of methyl glycolate and atom numbering (only s-cis forms about the $\mathrm{C}-\mathrm{O}$ central bond were studied-see text).

$0.47 e$, which compares with $0.45 e$ in the remaining forms ${ }^{1}$ ).

The $\mathrm{OH}$ bond length is also very slightly larger and the charge on the hydroxylic hydrogen slightly more positive $(0.46 e)$ in the second more stable conformer (Gsk) than in the higher energy conformers (see Table 1). These effects may be attributed to the existence in this form of a weak intramolecular hydrogen bond involving the $\mathrm{OH}$ group and the ester oxygen atom

\footnotetext{
${ }^{1} 1 e=1.6021892 \times 10^{-19} \mathrm{C}$; note that the calculated charge of $\mathrm{H}_{(7)}$ in Gsk is $0.46 e$, due to the presence in this form of a weaker $\mathrm{OH} \cdots \mathrm{OCH}_{3}$ intramolecular hydrogen bonding, as explained in detail below.
}

$\left(\mathrm{OH} \cdots \mathrm{OCH}_{3}\right)$. The relative weakness of this intramolecular hydrogen bond is not surprising, since it is well known that an ester oxygen is not able to establish hydrogen bonds as strong as those formed by the carbonyl oxygen atom [26,27]. However, this interaction may explain, at least in part, the lower energy of the Gsk conformer when compared with the Ga and Sa forms, where the orientation of the hydroxylic hydrogen relatively to the lone electron pairs of the ester oxygen does not seem to be as favorable as in the Gsk conformer. Assuming that the relative lowering in energy of forms Ss and Gsk relatively to the $\mathbf{G a}$ and Sa conformers are essentially due to the $\mathrm{OH} \cdots \mathrm{O}=$ or $\mathrm{OH} \cdots \mathrm{CH}_{3}$ intramolecular hydrogen bonding (what is 
Table 2

6-31G* calculated molecular structures, relative energies and dipole moments for the studied conformers of methyl $\alpha$-hydroxy isobutyrate (bond lengths in pm, angles in degrees, relative energies in $\mathrm{kJ} \mathrm{mol}^{-1}$, dipole moments in Debyes $(1 \mathrm{D}=3.33564 \times$ $10^{-30} \mathrm{C} \mathrm{m}$ ). See Fig. 2 for atom numbering)

\begin{tabular}{|c|c|c|c|}
\hline \multirow[t]{2}{*}{ Parameter } & \multicolumn{3}{|c|}{ Conformer } \\
\hline & Ss & Gsk & Ask \\
\hline $\mathrm{C}=\mathrm{O}$ & 119.2 & 118.7 & 118.9 \\
\hline $\mathrm{C}-\mathrm{C}$ & 152.7 & 153.0 & 153.0 \\
\hline $\mathrm{C}-\mathrm{O}$ & 131.7 & 132.7 & 131.8 \\
\hline $\mathrm{O}-\mathrm{C}\left(\mathrm{H}_{3}\right)$ & 142.0 & 141.9 & 141.6 \\
\hline $\mathrm{C}-\mathrm{O}(\mathrm{H})$ & 139.9 & 140.3 & 140.8 \\
\hline $\mathrm{OH}$ & 95.1 & 94.8 & 94.8 \\
\hline $\mathrm{C}-\mathrm{H}_{(10)}$ & 108.0 & 108.0 & 108.0 \\
\hline $\mathrm{C}-\mathrm{H}_{(11)}$ & 107.8 & 107.9 & 107.9 \\
\hline $\mathrm{C}-\mathrm{H}_{(12)}$ & 108.0 & 108.0 & 108.0 \\
\hline $\mathrm{C}-\mathrm{C}_{(7)}$ & 152.9 & 153.4 & 152.5 \\
\hline $\mathrm{C}-\mathrm{C}_{(8)}$ & 153.2 & 152.2 & 153.2 \\
\hline $\mathrm{C}-\mathrm{H}_{(13)}$ & 108.3 & 108.6 & 108.2 \\
\hline $\mathrm{C}-\mathrm{H}_{(14)}$ & 108.4 & 108.4 & 108.7 \\
\hline $\mathrm{C}-\mathrm{H}_{(15)}$ & 108.5 & 108.4 & 108.2 \\
\hline $\mathrm{C}-\mathrm{H}_{(16)}$ & 108.5 & 108.1 & 108.2 \\
\hline $\mathrm{C}-\mathrm{H}_{(17)}$ & 108.4 & 108.4 & 108.7 \\
\hline $\mathrm{C}-\mathrm{H}_{(18)}$ & 108.3 & 108.3 & 108.5 \\
\hline $\mathrm{C}-\mathrm{C}=\mathrm{O}$ & 122.9 & 125.0 & 123.9 \\
\hline $\mathrm{O}=\mathrm{C}-\mathrm{O}$ & 123.7 & 123.3 & 123.6 \\
\hline $\mathrm{C}-\mathrm{O}-\mathrm{C}$ & 117.2 & 117.1 & 117.0 \\
\hline $\mathrm{O}-\mathrm{C}-\mathrm{C}$ & 108.1 & 110.4 & 105.7 \\
\hline $\mathrm{H}-\mathrm{O}-\mathrm{C}$ & 109.0 & 109.5 & 109.0 \\
\hline $\mathrm{O}-\mathrm{C}-\mathrm{H}_{(10)}$ & 110.4 & 110.4 & 110.5 \\
\hline $\mathrm{O}-\mathrm{C}-\mathrm{H}_{(11)}$ & 105.7 & 105.9 & 105.8 \\
\hline $\mathrm{O}-\mathrm{C}-\mathrm{H}_{(12)}$ & 110.4 & 110.4 & 110.5 \\
\hline $\mathrm{C}-\mathrm{C}-\mathrm{C}_{(7)}$ & 110.5 & 107.7 & 109.8 \\
\hline $\mathrm{C}-\mathrm{C}-\mathrm{C}_{(8)}$ & 109.1 & 10.1 & 108.7 \\
\hline $\mathrm{C}-\mathrm{C}-\mathrm{H}_{(13)}$ & 111.7 & 110.8 & 111.5 \\
\hline $\mathrm{C}-\mathrm{C}-\mathrm{H}_{(14)}$ & 108.6 & 109.0 & 109.4 \\
\hline $\mathrm{C}-\mathrm{C}-\mathrm{H}_{(15)}$ & 110.4 & 111.3 & 110.4 \\
\hline $\mathrm{C}-\mathrm{C}-\mathrm{H}_{(16)}$ & 110.4 & 111.0 & 110.3 \\
\hline $\mathrm{C}-\mathrm{C}-\mathrm{H}_{(17)}$ & 108.7 & 109.0 & 109.7 \\
\hline $\mathrm{C}-\mathrm{C}-\mathrm{H}_{(18)}$ & 111.8 & 110.3 & 111.3 \\
\hline $\mathrm{C}-\mathrm{C}(=\mathrm{O})-\mathrm{O}$ & 178.9 & -176.6 & -177.4 \\
\hline $\mathrm{O}=\mathrm{C}-\mathrm{O}-\mathrm{C}$ & 0.0 & -0.9 & -2.0 \\
\hline $\mathrm{O}=\mathrm{C}-\mathrm{C}-\mathrm{O}$ & -5.7 & 148.3 & 132.7 \\
\hline $\mathrm{C}-\mathrm{C}-\mathrm{O}-\mathrm{H}$ & 9.8 & 49.4 & -179.7 \\
\hline $\mathrm{C}-\mathrm{O}-\mathrm{C}-\mathrm{H}_{(10)}$ & 60.6 & 60.5 & 60.6 \\
\hline $\mathrm{C}-\mathrm{O}-\mathrm{C}-\mathrm{H}_{(11)}$ & -60.6 & -60.5 & -60.6 \\
\hline $\mathrm{C}-\mathrm{O}-\mathrm{C}-\mathrm{H}_{(12)}$ & 180.0 & 180.0 & 180.0 \\
\hline $\mathrm{O}=\mathrm{C}-\mathrm{C}-\mathrm{C}_{(7)}$ & 123.9 & -91.0 & 13.5 \\
\hline $\mathrm{O}=\mathrm{C}-\mathrm{C}-\mathrm{C}_{(8)}$ & 113.1 & 30.8 & -108.9 \\
\hline $\mathrm{C}-\mathrm{C}-\mathrm{C}-\mathrm{H}_{(13)}$ & -64.1 & -60.6 & -61.2 \\
\hline $\mathrm{C}-\mathrm{C}-\mathrm{C}-\mathrm{H}_{(14)}$ & 175.6 & 180.4 & 178.8 \\
\hline $\mathrm{C}-\mathrm{C}-\mathrm{C}-\mathrm{H}_{(15)}$ & 57.4 & 60.2 & 59.4 \\
\hline $\mathrm{C}-\mathrm{C}-\mathrm{C}-\mathrm{H}_{(16)}$ & -58.0 & -59.6 & -61.1 \\
\hline $\mathrm{C}-\mathrm{C}-\mathrm{C}-\mathrm{H}_{(17)}$ & -176.1 & 179.8 & 179.4 \\
\hline
\end{tabular}

Table 2 (continued)

\begin{tabular}{lccc}
\hline Parameter & \multicolumn{3}{l}{ Conformer } \\
\cline { 2 - 4 } & Ss & Gsk & Ask \\
\hline $\mathrm{C}-\mathrm{C}-\mathrm{C}-\mathrm{H}_{(18)}$ & 63.5 & 61.0 & 60.2 \\
$\Delta E^{\mathrm{a}}$ & - & 6.6 & 20.9 \\
$|\mu|$ & 2.961 & 2.418 & 2.052 \\
\hline
\end{tabular}

${ }^{\text {a }}$ Relative energies to the most stable form. Calculated total energy for the Ss conformer is $-1101084.0 \mathrm{~kJ} \mathrm{~mol}^{-1}$.

supported by the fact that, except for the $\mathrm{OH}$ bond length and the $\mathrm{O}-\mathrm{C}-\mathrm{C}$ and $\mathrm{H}-\mathrm{O}-\mathrm{C}$ angles, bond lengths and bond angles in methyl glycolate do not change appreciably with conformation), the energies of these two interactions can be estimated as being ca. 11 and $2 \mathrm{~kJ} \mathrm{~mol}^{-1}$, respectively.

Forms As and Aa do not show any intramolecular hydrogen bonds and, in addition, exhibit important electrostatic repulsions between the lone electron pairs of the hydroxylic oxygen atom and the carbonyl or ester oxygen, respectively. Hence, their energies are much higher than those of the remaining conformers (larger than $20 \mathrm{~kJ} \mathrm{~mol}^{-1}$, when compared with the conformational ground state). The predicted higher energy for Aa than for As agrees well with the general trend for the ester oxygen atom in carboxylic esters to be systematically more negative and sterically more important than the carbonyl oxygen [26,27].

\subsubsection{Methyl $\alpha$-hydroxy isobutyrate}

Table 2 and Fig. 2 show the ab initio 6-31G* calculated geometries, relative energies and dipole moments for the three different s-cis $(\mathrm{C}-\mathrm{O})$ conformers found in the PES of methyl $\alpha$-hydroxy isobutyrate. These conformers correspond to the Ss, Gsk and Ask forms (see Fig. 2), the first two forms being structurally similar to the analogous conformers of methyl glycolate and the third being the equivalent form of the Aa conformer of methyl glycolate, with the heavy atom skeleton distorted from planarity due to the additional steric repulsions associated with the extra methyl groups. Like in the unsubstituted molecule, the lowest energy form of methyl $\alpha$-hydroxy isobutyrate is the Ss conformer, which is more stable than the Gsk and Ask forms by 6.6 and $20.9 \mathrm{~kJ} \mathrm{~mol}^{-1}$, respectively.

As for methyl glycolate, the relative energies of the 


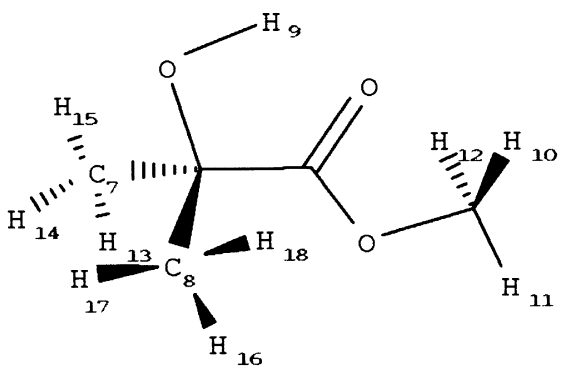

Syn-syn (Ss)

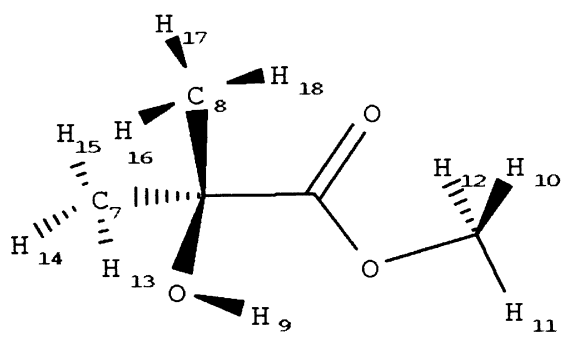

Gauche-skew (Gsk)

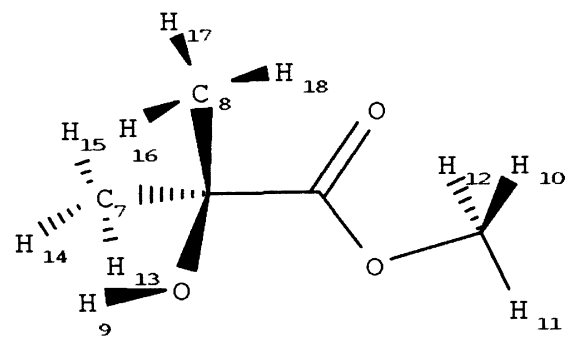

Anti-skew (Ask)

Fig. 2. Conformers of methyl $\alpha$-hydroxy isobutyrate and atom numbering (only s-cis forms about the $\mathrm{C}-\mathrm{O}$ central bond were studied-see text).

different conformers can be explained by considering the participation of the hydroxyl group in an intramolecular hydrogen bonding interaction with the carbonyl oxygen (in the most stable Ss conformer) or with the ester oxygen (in Gsk), and the oxygen- oxygen repulsion occurring in the Ask form. It is worth noting that the results also seem to indicate that the $\mathrm{OH} \cdots \mathrm{O}=$ intramolecular hydrogen bonding in $\alpha$-hydroxy isobutyrate is slightly weaker than in methyl glycolate by ca. $2.5 \mathrm{~kJ} \mathrm{~mol}^{-1}$, a result that is in agreement with the expected electron releasing ability of the two $\alpha$-methyl substituents, which makes the hydroxylic hydrogen less acid (the calculated charge of the hydroxyl oxygen in $\alpha$-hydroxy isobutyrate is $-0.77 e$, while in methyl glycolate this charge is only $-0.74 e$ ).

The absence of equivalent conformers to the $\mathbf{G a}, \mathbf{S a}$ and As forms of methyl glycolate is a direct consequence of the more restricted conformational space of the dimethyl substituted molecule, induced by the additional steric repulsions involving the extra methyl groups and either the carbonyl oxygen (in the case of the two first species) or ester oxygen (in the As conformation).

Together, the two most stable conformers of methyl $\alpha$-hydroxy isobutyrate represent approximately $100 \%$ of the total conformational population at room temperature (Ss: 88\%; Gsk: 12\%; Ask: $<0.05 \%$ ) and thus, as for methyl glycolate, only two conformers are accessible to vibrational spectroscopic measurements undertaken under normal experimental conditions.

\subsection{Vibrational spectra}

\subsubsection{Methyl glycolate}

Methyl glycolate has 30 fundamental vibrations, all active both in infrared and Raman. In the most stable Ss conformer $\left(\mathrm{C}_{\mathrm{s}}\right.$ point group $)$ the normal coordinates span the irreducible representations $19 \mathrm{~A}^{\prime}+11 \mathrm{~A}^{\prime \prime}$. Table 3 presents the definition of the symmetry coordinates used in the vibrational calculations. The calculated spectra, vibrational assignments and potential energy distributions (PEDs) are shown in Table 4. The spectra are shown in Figs. 3-5.

In general, the assignments of the most stable conformer of the matrix isolated methyl glycolate agree with those previously proposed by Hollenstein et al. [16]. Exceptions are the following:

1. The calculations predict that the $\nu \mathrm{CH}_{2}$ as. mode shall occur at a higher frequency than the $\nu \mathrm{CH}_{2} \mathrm{~s}$. vibration (calculated values: 2911 vs. $2881 \mathrm{~cm}^{-1}$, 


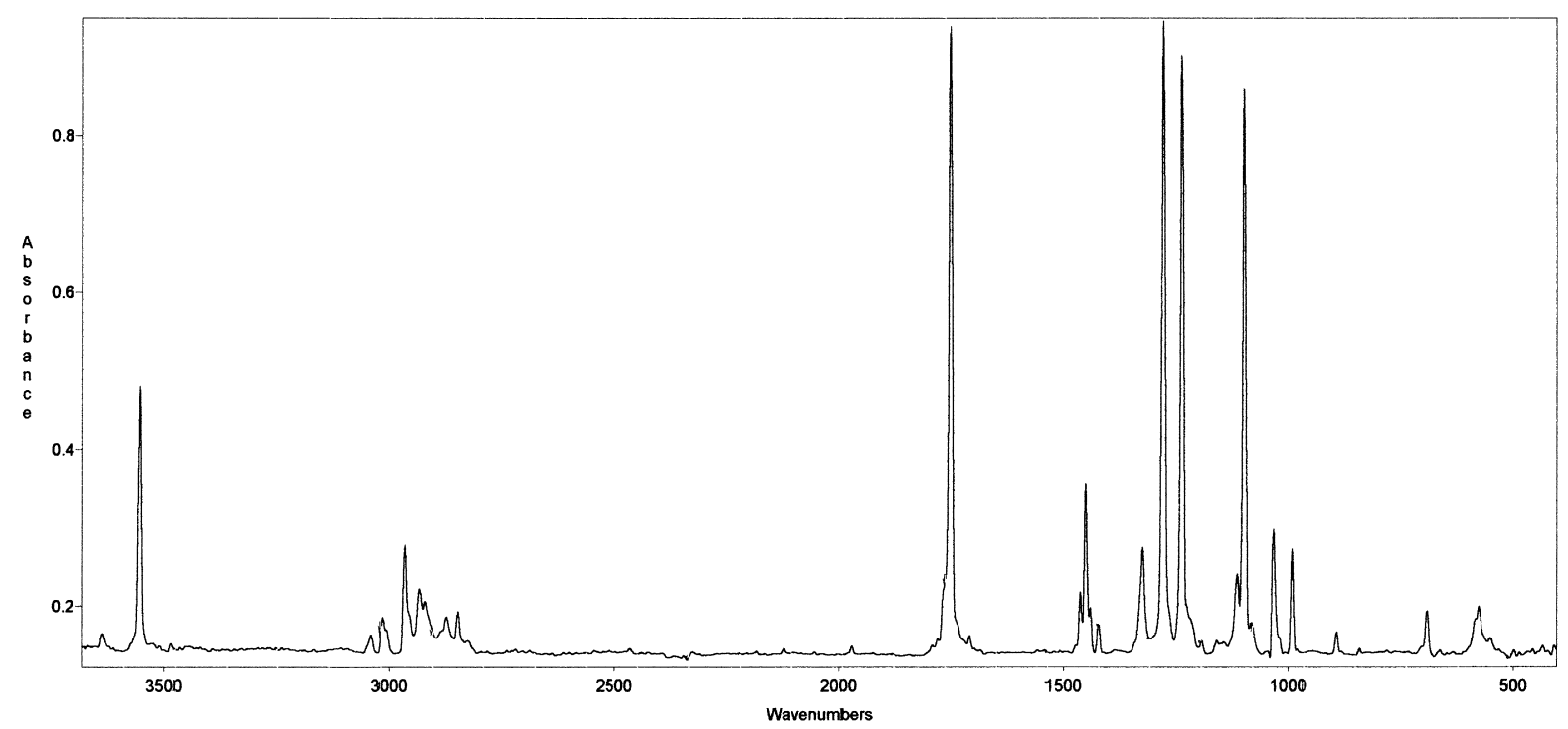

Fig. 3. MIS infrared spectrum of methyl glycolate in a argon matrix $(\mathrm{M} / \mathrm{S}$ ratio $\approx 1000 ; T=17 \mathrm{~K})$.

respectively). In the absence of a reliable theoretical prediction, Hollenstein et al. proposed the assignment of the two-methylene stretching modes in the opposite order. These assignments are now reversed, in order to be consistent with the theoretical data.

2. The assignment of the $\nu \mathrm{C}-\mathrm{O}$ and $\delta \mathrm{COH}$ modes are now also reversed with respect to the previous study. The theoretical predictions clearly indicate that these two coordinates are considerably mixed, both contributing to the strong infrared bands predicted to occur at 1288 and $1256 \mathrm{~cm}^{-1}$ (which have experimental counterparts at 1277 and $1235 \mathrm{~cm}^{-1}$ ). However, $\nu \mathrm{C}-\mathrm{O}$ is predicted to have a minor contribution to the lower frequency band, while $\delta \mathrm{COH}$ has important contributions to both bands. Then, upon deuteration of the hydroxylic group, both the 1277 and $1235 \mathrm{~cm}^{-1}$ shall red shift. Since in the matrix isolated infrared spectra of the $\mathrm{CH}_{2} \mathrm{ODC}(=\mathrm{O}) \mathrm{OCH}_{3}$ isotopomer of methyl glycolate, the bands ascribable to $\nu \mathrm{C}-\mathrm{O}$ and $\delta \mathrm{COH}$ occur at 1239 and $986 \mathrm{~cm}^{-1}$, respectively [16], $\nu \mathrm{C}-\mathrm{O}$ in the light isotopomer must be necessarily assigned to the band at $1277 \mathrm{~cm}^{-1}$ (which red shifts in the deuterated molecule by $38 \mathrm{~cm}^{-1}$ ), while the band at $1235 \mathrm{~cm}^{-1}$ is better assigned to the $\delta \mathrm{COH}$ mode (which appears red shifted by $249 \mathrm{~cm}^{-1}$ in the deuterated species).
3. The $\mathrm{twCH}_{2}$ mode (calculated value: $1227 \mathrm{~cm}^{-1}$ ), that had not been previously assigned is now attributed to the weak band at $1219 \mathrm{~cm}^{-1}$. This band is observed at a frequency that is similar to that of the lower component band of a Fermi doublet assigned to this mode and the first overtone of the $\mathrm{OH}$ carboxylic torsion in glycolic acid (1231, $1216 \mathrm{~cm}^{-1}$ [16]).

4. The $1400 \mathrm{~cm}^{-1}$ region of the infrared spectrum of the matrix isolated methyl glycolate is very crowded and the assignments cannot be made without any doubt. However, taking into consideration the results of the theoretical predictions, the assignments here made for the three methyl bending modes and the methylene scissoring and wagging vibrations, which are predicted to give rise to bands in this spectral region, also slightly differ from those formerly proposed.

A significant number of bands in the MIS infrared spectra could be ascribed to the Gsk conformer of methyl glycolate (see Table 4). As for the most stable conformer, the calculated and experimental vibrational data for this form agree very well with respect to both frequencies and relative intensities.

The $\nu \mathrm{C}-\mathrm{C}$ bands originated in the two conformers (Ss: $892 \mathrm{~cm}^{-1}$; Gsk: $842 \mathrm{~cm}^{-1}$ ) are particularly useful to estimate their relative populations in the gaseous 


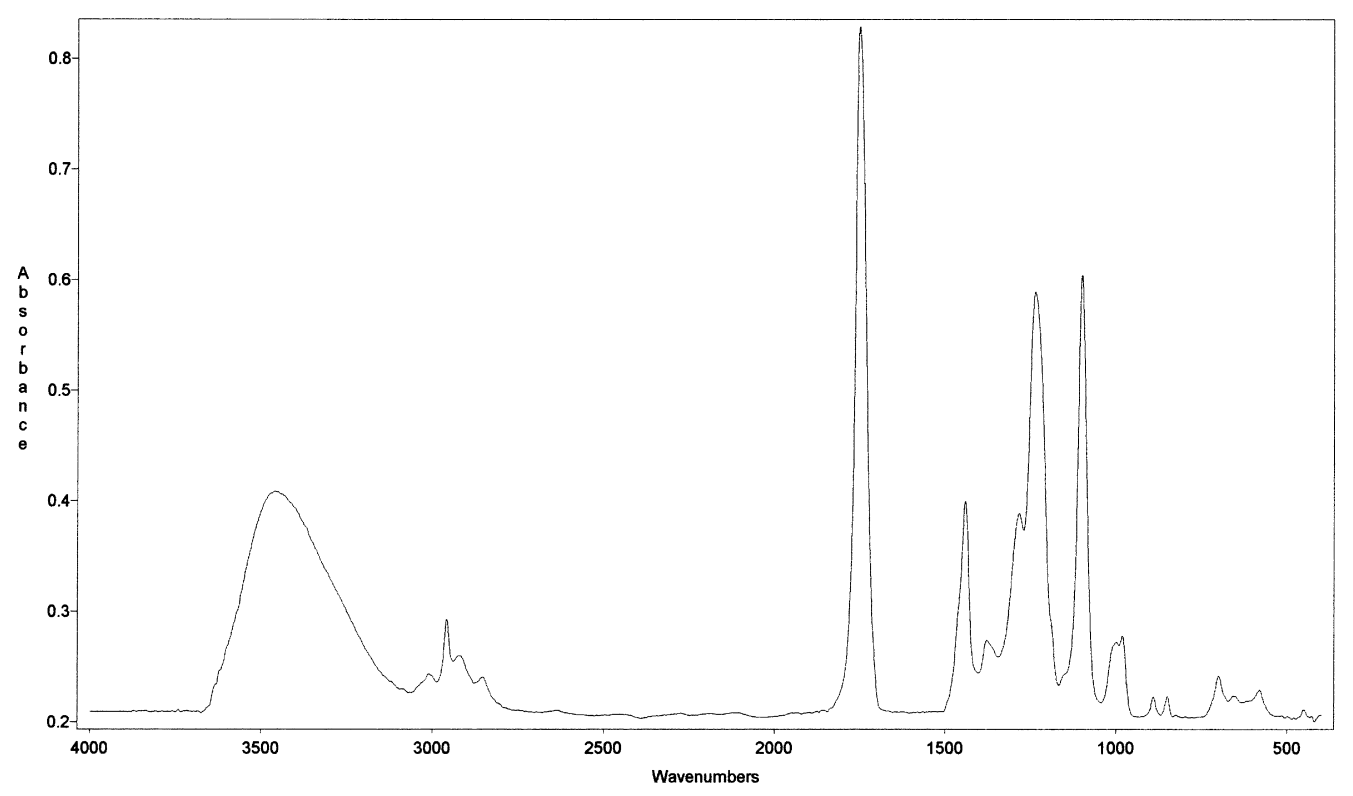

Fig. 4. Liquid phase infrared spectrum of methyl glycolate at room temperature.

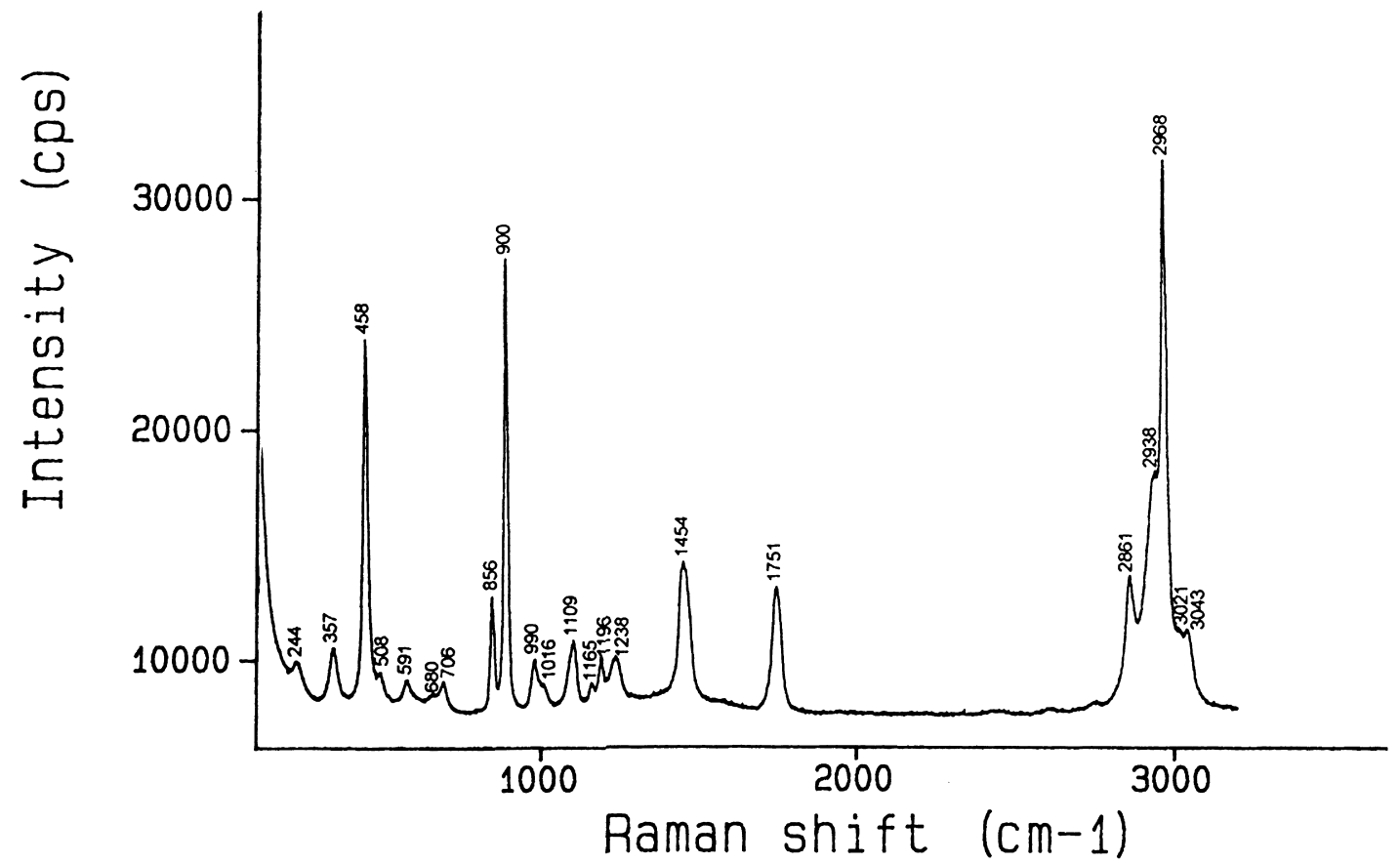

Fig. 5. Liquid phase Raman spectrum of methyl glycolate at room temperature. 
Table 3

Definition of the internal symmetry coordinates of methyl glycolate used in the normal coordinate analysis (see Fig. 1 for atom numbering. Normalization constants are not given here; they are chosen as $N=\left(\sum c_{i}^{2}\right)^{-1 / 2}$, where $c_{i}$ are the coefficients of the individual valence coordinates; $\nu$, bond stretching; $\delta$, bending; $\omega$, wagging; $\rho$, rocking; tw, twisting; $\tau$, torsion; as., asymmetric; s., symmetric)

\begin{tabular}{|c|c|c|c|}
\hline & Approximate description & Symmetry $^{a}$ & Definition \\
\hline $\mathrm{S}_{1}$ & $\nu \mathrm{C}=\mathrm{O}$ & $\mathrm{A}^{\prime}$ & $\nu \mathrm{C}=\mathrm{O}$ \\
\hline $\mathrm{S}_{2}$ & $\nu \mathrm{C}-\mathrm{O}$ & $\mathrm{A}^{\prime}$ & $\nu \mathrm{C}-\mathrm{O}$ \\
\hline $\mathrm{S}_{3}$ & $\nu \mathrm{O}-\mathrm{C}\left(\mathrm{H}_{3}\right)$ & $\mathrm{A}^{\prime}$ & $\nu \mathrm{O}-\mathrm{C}\left(\mathrm{H}_{3}\right)$ \\
\hline $\mathrm{S}_{4}$ & $\nu \mathrm{C}-\mathrm{O}(\mathrm{H})$ & $\mathrm{A}^{\prime}$ & $\nu \mathrm{C}-\mathrm{O}(\mathrm{H})$ \\
\hline $\mathrm{S}_{5}$ & $\nu \mathrm{C}-\mathrm{C}$ & $\mathrm{A}^{\prime}$ & $\nu \mathrm{C}-\mathrm{C}$ \\
\hline $\mathrm{S}_{6}$ & $\nu \mathrm{CH}_{2} \mathrm{~s}$ & $\mathrm{~A}^{\prime}$ & $\nu \mathrm{CH}_{(8)}+\nu \mathrm{CH}_{(9)}$ \\
\hline $\mathrm{S}_{7}$ & $\nu \mathrm{CH}_{3}$ as'. & $\mathrm{A}^{\prime}$ & $2 \nu \mathrm{CH}_{(11)}-\nu \mathrm{CH}_{(10)}-\nu \mathrm{CH}_{(12)}$ \\
\hline $\mathrm{S}_{8}$ & $\nu \mathrm{CH}_{3} \mathrm{~s}$ & $\mathrm{~A}^{\prime}$ & $\nu \mathrm{CH}_{(11)}+\nu \mathrm{CH}_{(10)}+\nu \mathrm{CH}_{(12)}$ \\
\hline $\mathrm{S}_{9}$ & $\nu \mathrm{O}-\mathrm{H}$ & $\mathrm{A}^{\prime}$ & $\nu \mathrm{O}-\mathrm{H}$ \\
\hline$S_{10}$ & $\delta \mathrm{O}=\mathrm{C}-\mathrm{O}$ & $\mathrm{A}^{\prime}$ & $2 \delta \mathrm{O}=\mathrm{C}-\mathrm{O}-\delta \mathrm{CC}=\mathrm{O}-\delta \mathrm{CCO}$ \\
\hline$S_{11}$ & $\delta \mathrm{CC}=\mathrm{O}$ & $\mathrm{A}^{\prime}$ & $\delta \mathrm{CC}=\mathrm{O}-\delta \mathrm{CCO}$ \\
\hline$S_{12}$ & $\delta \mathrm{COC}$ & $\mathrm{A}^{\prime}$ & $\delta \mathrm{COC}$ \\
\hline$S_{13}$ & $\delta \mathrm{OCC}$ & $\mathrm{A}^{\prime}$ & $4 \delta \mathrm{OCC}-\delta \mathrm{CCH}_{(8)}-\delta \mathrm{CCH}_{(9)}-\delta \mathrm{OCH}_{(8)}-\delta \mathrm{OCH}_{(9)}$ \\
\hline $\mathrm{S}_{14}$ & $\delta \mathrm{CH}_{2}$ & $\mathrm{~A}^{\prime}$ & $5 \delta \mathrm{HCH}-\delta \mathrm{OCC}-\delta \mathrm{CCH}_{(8)}-\delta \mathrm{CCH}_{(9)}-\delta \mathrm{OCH}_{(8)}-\delta \mathrm{OCH}_{(9)}$ \\
\hline $\mathrm{S}_{15}$ & $\omega \mathrm{CH}_{2}$ & $A^{\prime}$ & $\delta \mathrm{CCH}_{(8)}+\delta \mathrm{CCH}_{(9)}-\delta \mathrm{OCH}_{(8)}-\delta \mathrm{OCH}_{(9)}$ \\
\hline$S_{16}$ & $\delta \mathrm{CH}_{3}$ as $^{\prime}$. & $\mathrm{A}^{\prime}$ & $2 \delta \mathrm{H}_{(10)} \mathrm{CH}_{(12)}-\delta \mathrm{H}_{(11)} \mathrm{CH}_{(10)}-\delta \mathrm{H}_{(11)} \mathrm{CH}_{(12)}$ \\
\hline$S_{17}$ & $\delta \mathrm{CH}_{3} \mathrm{~s}$. & $\mathrm{A}^{\prime}$ & $\delta \mathrm{H}_{(10)} \mathrm{CH}_{(12)}+\delta \mathrm{H}_{(11)} \mathrm{CH}_{(10)}+\delta \mathrm{H}_{(11)} \mathrm{CH}_{(12)}-\delta \mathrm{CCH}_{(12)}-\delta \mathrm{CCH}_{(10)}-\delta \mathrm{CCH}_{(12)}$ \\
\hline $\mathrm{S}_{18}$ & $\rho \mathrm{CH}_{3}{ }^{\prime}$ & $\mathrm{A}^{\prime}$ & $2 \delta \mathrm{CCH}_{(12)}-\delta \mathrm{CCH}_{(10)}-\delta \mathrm{CCH}_{(12)}$ \\
\hline $\mathrm{S}_{19}$ & $\delta \mathrm{COH}$ & $\mathrm{A}^{\prime}$ & $\delta \mathrm{COH}$ \\
\hline$S_{20}$ & $\nu \mathrm{CH}_{2}$ as & $\mathrm{A}^{\prime \prime}$ & $\nu \mathrm{CH}_{(8)}-\nu \mathrm{CH}_{(9)}$ \\
\hline$S_{21}$ & $\nu \mathrm{CH}_{3}$ as". & $\mathrm{A}^{\prime \prime}$ & $\nu \mathrm{CH}_{(10)}-\nu \mathrm{CH}_{(12)}$ \\
\hline$S_{22}$ & $\delta \mathrm{CH}_{3}$ as". & $A^{\prime \prime}$ & $\delta \mathrm{H}_{(11)} \mathrm{CH}_{(10)}-\delta \mathrm{H}_{(11)} \mathrm{CH}_{(12)}$ \\
\hline$S_{23}$ & $\rho \mathrm{CH}_{3}^{\prime \prime}$ & $\mathrm{A}^{\prime \prime}$ & $\delta \mathrm{CCH}_{(10)}-\delta \mathrm{CCH}_{(12)}$ \\
\hline $\mathrm{S}_{24}$ & $\mathrm{TwCH}_{2}$ & $\mathrm{~A}^{\prime \prime}$ & $\delta \mathrm{CCH}_{(8)}-\delta \mathrm{CCH}_{(9)}-\delta \mathrm{OCH}_{(8)}+\delta \mathrm{OCH}_{(9)}$ \\
\hline$S_{25}$ & $\rho \mathrm{CH}_{2}{ }^{\prime \prime}$ & $A^{\prime \prime}$ & $\delta \mathrm{CCH}_{(8)}-\delta \mathrm{CCH}_{(9)}+\delta \mathrm{OCH}_{(8)}-\delta \mathrm{OCH}_{(9)}$ \\
\hline$S_{26}$ & $\rho \mathrm{C}=\mathrm{O}$ & $A^{\prime \prime}$ & $\rho \mathrm{C}=\mathrm{O}$ \\
\hline$S_{27}$ & $\tau \mathrm{C}-\mathrm{O}$ & $A^{\prime \prime}$ & $\tau \mathrm{C}-\mathrm{O}$ \\
\hline $\mathrm{S}_{28}$ & $\tau \mathrm{C}-\mathrm{C}$ & $A^{\prime \prime}$ & $\tau \mathrm{C}-\mathrm{C}$ \\
\hline $\mathrm{S}_{29}$ & $\tau \mathrm{C}-\mathrm{O}(\mathrm{H})$ & $A^{\prime \prime}$ & $\tau \mathrm{C}-\mathrm{O}(\mathrm{H})$ \\
\hline $\mathrm{S}_{30}$ & $\tau \mathrm{O}-\mathrm{C}\left(\mathrm{H}_{3}\right)$ & $A^{\prime \prime}$ & $\tau \mathrm{O}-\mathrm{C}\left(\mathrm{H}_{3}\right)$ \\
\hline
\end{tabular}

${ }^{\text {a }}$ Symmetry species of the coordinate in those conformers belonging to the $\mathrm{C}_{\mathrm{s}}$ point group (Ss, As, Aa).

phase, at the temperature of the pre-mixture used to prepare the matrix $(298 \mathrm{~K})$, since these bands lie in a clean spectral region. Taking into consideration the calculated relative intrinsic intensities of the $\nu \mathrm{C}-\mathrm{C}$ bands in each conformer, and the corresponding observed intensities, a population ratio Gsk:Ss of 0.043 could be obtained. This value agrees very well with the predicted value obtained from the calculated relative conformational energies (0.054).

The assignment of both Raman and infrared spectra of the pure liquid did not present any major difficulty, since most of the bands do not exhibit large shifts in frequency when compared with the isolated molecule data (see Table 4). Due to band broadening, the number of observed bands in the liquid phase spectra that could be assigned to the Gsk conformer is smaller than in the MIS spectrum. However, using the relative intensities of the $\nu \mathrm{C}-\mathrm{C}$ bands assigned to the two conformers to estimate the Gsk:Ss population ratio in the pure liquid at room temperature (Raman bands are more intense than their infrared counterparts and were used here), it could be observed that the population of the Gsk conformer increases considerably with respect to the gas phase situation. The Gsk:Ss population ratio obtained by this way (0.457) indicates that the $\Delta E_{\mathrm{Gsk}}-\mathrm{Ss}$ energy difference reduces to slightly more than one-third of the gas 
Table 4

Calculated $\left(6-31 \mathrm{G}^{*}\right)$ and experimental vibrational spectra of methyl glycolate and potential energy distribution (PED) (wavenumbers in $\mathrm{cm}^{-1} ; \nu$, stretching; $\delta$, bending; $\omega$, wagging; tw, twisting; $\rho$, rocking; $\tau$, torsion, s., symmetric; as., asymmetric)

\begin{tabular}{|c|c|c|c|c|c|c|c|c|c|c|c|c|c|c|c|c|c|c|c|c|}
\hline \multirow[b]{4}{*}{$\begin{array}{l}\text { Approximate } \\
\text { description }\end{array}$} & \multicolumn{10}{|c|}{ Conformer $\mathrm{Ss}$ (point group: $\mathrm{C}_{\mathrm{s}}$ ) } & \multicolumn{10}{|c|}{ Conformer Gsk (point group: $\mathrm{C}_{1}$ ) } \\
\hline & \multirow{2}{*}{\multicolumn{3}{|c|}{ Calculated $^{\mathrm{a}}$}} & \multicolumn{7}{|c|}{ Experimental $^{\mathrm{b}}$} & \multicolumn{3}{|c|}{ Calculated $^{\mathrm{a}}$} & \multicolumn{7}{|c|}{ Experimental $^{\mathrm{b}}$} \\
\hline & & & & MIS(i.r.) & & Liquid & & & & & & & & $\operatorname{MIS}(\mathrm{i}$ & & Liquid & & & & \\
\hline & $\nu$ & $I_{\mathrm{i}, \mathrm{r}}$ & $I_{\mathrm{R}}$ & $\nu$ & $I$ & $\nu_{\mathrm{i}, \mathrm{r}}$ & $I_{\mathrm{i}, \mathrm{r}}$ & $\nu_{\mathrm{R}}$ & $I_{\mathrm{R}}$ & $\mathrm{PED}^{\mathrm{c}}$ & $\nu$ & $I_{\mathrm{i}, \mathrm{r}}$ & $I_{\mathrm{R}}$ & $\nu$ & $I$ & $\nu_{\mathrm{i} . \mathrm{r}}$ & $I_{\mathrm{i}, \mathrm{r}}$ & $\nu_{\mathrm{R}}$ & $I_{\mathrm{R}}$ & $\mathrm{PED}^{\mathrm{c}}$ \\
\hline$\nu \mathrm{OH}$ & 3633 & 98 & 30 & 3554 & 119 & 3463 & $\mathrm{~s}, \mathrm{vbr}$ & n.o. & & $S_{9}(100)$ & 3677 & 68 & 41 & 3631 & 63 & 3463 & $\mathrm{~s}, \mathrm{vbr}$ & n.o. & & $S_{9}(100)$ \\
\hline$\nu \mathrm{CH}_{3}$ as.' & 3004 & 24 & 70 & 3040 & 13 & 3041 & vw & 3043 & 17 & $\mathrm{~S}_{7}(99)$ & 3001 & 25 & 66 & 3040 & & 3041 & $\mathrm{vw}$ & 3043 & & $\mathrm{~S}_{7}(99)$ \\
\hline$\nu \mathrm{CH}_{3}$ as." & 2986 & 28 & 44 & 3015 & 19 & 3013 & $\mathrm{w}$ & 3021 & 9 & $\mathrm{~S}_{21}(100)$ & 2988 & 27 & 45 & 3015 & & 3013 & $\mathrm{w}$ & 3021 & & $S_{21}(100)$ \\
\hline$\nu \mathrm{CH}_{3} \mathrm{~s}$ & 2912 & 31 & 100 & 2967 & 43 & 2959 & $\mathrm{~m}$ & 2968 & 115 & $\mathrm{~S}_{8}(99)$ & 2912 & 3 & 102 & 2960 & 63 & 2959 & $\mathrm{~m}$ & 2968 & & $\mathrm{~S}_{8}(99)$ \\
\hline$\nu \mathrm{CH}_{2}$ as. & 2911 & 34 & 68 & 2935 & 25 & n.o. & & $2938^{d}$ & 20 & $\mathrm{~S}_{20}(100)$ & 2973 & 15 & 77 & 3006 & 63 & n.o. & & 2938 & & $S_{20}(66)+S_{6}(33)$ \\
\hline$\nu \mathrm{CH}_{2} \mathrm{~s}$ & 2881 & 30 & 112 & 2921 & 21 & 2919 & $\mathrm{w}$ & & 33 & $\mathrm{~S}_{6}(100)$ & 2853 & 43 & 99 & 2873 & 63 & 2852 & w & 2861 & 64 & $\mathrm{~S}_{6}(65)+\mathrm{S}_{20}(35)$ \\
\hline$\nu \mathrm{C}=\mathrm{O}$ & 1793 & 318 & 4 & 1752 & 266 & 1750 & vs & 1751 & 26 & $\mathrm{~S}_{1}(81)$ & 1810 & 297 & 4 & 1768 & 177 & n.o. & & n.o. & & $\mathrm{S}_{1}(81)$ \\
\hline$\delta \mathrm{CH}_{2}$ & 1479 & 10 & 12 & 1463 & 31 & & & & 8 & $\mathrm{~S}_{14}(86)$ & 1467 & 1 & 14 & 1445 & & 1441 & $\mathrm{~m}$ & & & $S_{14}(79)$ \\
\hline$\delta \mathrm{CH}_{3}$ as. $^{\prime}$ & 1472 & 7 & 11 & $1450^{\mathrm{d}}$ & 28\{ & 1460 & sh & & 7 & $S_{16}(61)+S_{17}(23)$ & 1472 & 7 & 11 & 1450 & & & & & & $\mathrm{~S}_{16}(81)$ \\
\hline$\omega \mathrm{CH}_{2}$ & 1470 & 9 & 2 & & $37 \mathrm{C}$ & & & $1454^{\mathrm{d}}$ & 1 & $\mathrm{~S}_{15}(16)+\mathrm{S}_{17}(24)+\mathrm{S}_{16}(24)$ & 1400 & 122 & 3 & 1421 & 104 & n.o. & & 1454 & & $\mathrm{~S}_{15}(53)+\mathrm{S}_{19}(22)$ \\
\hline$\delta \mathrm{CH}_{3}$ as." & 1467 & 5 & 17 & 1445 & 18\{ & 1441 & & & 11 & $\mathrm{~S}_{22}(95)$ & 1467 & 5 & 16 & 1445 & & 1441 & & & & $\mathrm{~S}_{22}(91)$ \\
\hline$\delta \mathrm{CH}_{3} \mathrm{~s}$ & 1440 & 4 & 7 & 1440 & $18 l$ & $x^{1+41}$ & & & 5 & $S_{17}(42)+S_{15}(29)+S_{9}(15)$ & 1459 & 11 & 5 & 1440 & & & & & & $\mathrm{~S}_{17}(79)$ \\
\hline$\nu \mathrm{C}-\mathrm{O}$ & 1288 & 560 & 2 & 1277 & 269 & 1284 & $\mathrm{~m}, \mathrm{br}$ & n.o. & & $\mathrm{S}_{2}(32)+\mathrm{S}_{19}(32)$ & 1298 & 389 & 1 & 1323 & 302\{ & 1377 & $\mathrm{~m}$ & n.o. & & $S_{2}(40)+S_{15}(39)+S_{10}(13)$ \\
\hline$\delta \mathrm{COH}$ & 1256 & 75 & 1 & 1235 & 259 & 1236 & $\mathrm{~s}$ & $1238^{\mathrm{d}}$ & 1 & $S_{19}(39)+S_{15}(39)+S_{2}(18)$ & 1327 & 39 & 6 & 1337 & $42 l$ & & & 1337 & 3 & $S_{19}(30)+S_{15}(23)+S_{24}(13)$ \\
\hline $\mathrm{TwCH}_{2}$ & 1227 & $<1$ & 12 & 1219 & 3 & n.o. & & & & $\mathrm{S}_{24}(96)$ & 1187 & 45 & 4 & n.o. & & n.o. & & 1196 & & $S_{24}(50)+S_{19}(24)$ \\
\hline$\rho \mathrm{CH}_{3}{ }^{\prime}$ & 1196 & 7 & 5 & 1191 & 6 & 1194 & sh & 1196 & 9 & $\mathrm{~S}_{18}(75)$ & 1198 & 8 & 5 & 1191 & & 1194 & sh & & & $\mathrm{S}_{18}(72)$ \\
\hline$\rho \mathrm{CH}_{3}^{\prime \prime}$ & 1159 & 4 & 4 & 1159 & 3 & 1148 & vw & 1165 & 4 & $\mathrm{~S}_{23}(91)$ & 1159 & 4 & 4 & 1159 & & 1148 & vw & 1165 & & $\mathrm{~S}_{23}(93)$ \\
\hline$\nu \mathrm{C}-\mathrm{O}(\mathrm{H})$ & 1097 & 194 & 5 & 1097 & 250 & 1099 & $\mathrm{~s}$ & 1109 & 12 & $\mathrm{~S}_{4}(73)+\mathrm{S}_{19}(11)$ & 1116 & 133 & 5 & 1113 & 167 & n.o. & & 1109 & & $S_{4}(76)$ \\
\hline$\rho \mathrm{CH}_{2}$ & 1029 & 2 & $<1$ & 1018 & 4 & n.o. & & 1016 & 3 & $S_{25}(67)+S_{26}(21)$ & 997 & 30 & 2 & 995 & 34 & 999 & sh & 1016 & & $S_{25}(60)+S_{26}(19)$ \\
\hline$\nu \mathrm{O}-\mathrm{C}\left(\mathrm{H}_{3}\right)$ & 997 & 33 & 3 & 991 & 48 & 981 & $\mathrm{w}$ & 990 & 9 & $S_{3}(76)$ & 1030 & 57 & 4 & 1028 & 104 & n.o. & & & & $S_{3}(71)+S_{5}(10)$ \\
\hline$\nu \mathrm{C}-\mathrm{C}$ & 883 & 5 & 8 & 892 & 9 & 891 & $\mathrm{vw}$ & 900 & 94 & $\mathrm{~S}_{5}(31)+\mathrm{S}_{2}(18)+\mathrm{S}_{10}(11)$ & 840 & 29 & 8 & 842 & 33 & 848 & $\mathrm{vw}$ & 856 & 43 & $\begin{array}{l}S_{5}(15)+S_{2}(33)+S_{10}(16)+ \\
S_{19}(13)\end{array}$ \\
\hline$\delta \mathrm{O}=\mathrm{C}-\mathrm{O}$ & 681 & 26 & 3 & 691 & 20 & 699 & $\mathrm{w}$ & 706 & 5 & $\mathrm{~S}_{10}(34)+\mathrm{S}_{13}(22)+\mathrm{S}_{5}(16)$ & 670 & 22 & 3 & 663 & 27 & 663 & $\mathrm{vw}$ & 680 & 4 & $S_{10}(16)+S_{26}(26)$ \\
\hline$\rho \mathrm{C}=\mathrm{O}$ & 571 & 42 & 1 & 576 & 32 & 579 & $\mathrm{w}$ & 591 & 4 & $S_{26}(55)+S_{25}(18)+S_{27}(15)$ & 569 & 22 & 4 & 550 & 27 & n.o. & & n.o. & & $S_{26}(35)+S_{5}(17)+S_{10}(14)$ \\
\hline$\delta \mathrm{CC}=\mathrm{O}$ & 435 & 1 & 4 & 434 & 2 & 450 & $\mathrm{vw}$ & 458 & 76 & $\mathrm{~S}_{11}(27)+\mathrm{S}_{5}(23)+\mathrm{S}_{13}(17)$ & 464 & 9 & 3 & 457 & 10 & n.o. & & 508 & 5 & $S_{11}(34)+S_{13}(18)+S_{26}(12)$ \\
\hline$\delta \mathrm{COC}$ & 333 & 38 & $<1$ & $343^{\mathrm{e}}$ & 41 & & & 357 & 9 & $\begin{array}{l}S_{12}(39)+S_{13}(27)+S_{10}(15)+ \\
S_{11}(15)\end{array}$ & 327 & 117 & 1 & & & & & 357 & & $S_{12}(25)+S_{29}(32)+S_{11}(21)$ \\
\hline$\tau \mathrm{C}-\mathrm{O}(\mathrm{H})$ & 258 & 77 & 1 & $303^{\mathrm{e}}$ & 96 & & & 244 & 8 & $S_{29}(76)$ & 300 & 99 & 2 & & & & & 244 & & $S_{29}(58)+S_{12}(27)$ \\
\hline$\delta \mathrm{OCC}$ & 209 & $<1$ & $<1$ & & & & & & & $S_{13}(20)+S_{11}(40)+S_{12}(28)$ & 200 & 10 & $<1$ & & & & & & & $S_{13}(17)+S_{11}(39)+S_{12}(17)$ \\
\hline$\tau \mathrm{O}-\mathrm{C}\left(\mathrm{H}_{3}\right)$ & 151 & 16 & $<1$ & & & & & & & $S_{30}(46)+S_{27}(16)+S_{29}(15)$ & 158 & 2 & $<1$ & & & & & & & $S_{30}(53)+S_{27}(34)$ \\
\hline$\tau \mathrm{C}-\mathrm{O}$ & 131 & 7 & $<1$ & & & & & & & $S_{27}(49)+S_{30}(46)$ & 136 & 2 & $<1$ & & & & & & & $S_{27}(43)+S_{29}(46)$ \\
\hline$\tau \mathrm{C}-\mathrm{C}$ & 35 & 23 & $<1$ & & & & & & & $\mathrm{~S}_{28}(45)+\mathrm{S}_{29}(43)$ & 72 & 3 & $<1$ & & & & & & & $\mathrm{~S}_{28}(72)$ \\
\hline
\end{tabular}

${ }^{a}$ Calculated i.r. intensities in $\mathrm{km} \mathrm{mol}^{-1}$; calculated Raman activities in a.m.u. $\AA^{2}$.

${ }^{\mathrm{b}}$ Wavenumber values shown in bold represent bands considering to have contributions from both conformers; MIS intensities were normalized to the total calculated intensities of the bands which have an experimental counterpart by using the formula $I_{(i)}=I_{(i)}^{\mathrm{obs}} \times \sum_{j=1, n} I_{(j)}^{\mathrm{obs}} / \sum_{j=1, n} I_{(j)}^{\mathrm{calc}}$, where the sums extend to all bands observed (the intensity of the bands ascribed to both conformers is here assumed to be due only to the most stable form, since the expected contribution to these bands due to the higher energy conformer is small); a similar procedure was adopted in the case of the experimental Raman activities; liquid phase i.r. intensities were shown in a qualitative way using the usual notation.

${ }^{\mathrm{c}}$ See Table 3 for definition of symmetry coordinates; only PED values greater than 10 are shown.

${ }^{\mathrm{d}}$ Experimental intensities of the component bands were estimated by dividing the total observed intensity in consonance with their calculated intensity ratios.

${ }^{\mathrm{e}}$ From Ref. [16]. 
Table 5

Definition of the internal symmetry coordinates of methyl $\alpha$-hydroxyisobutyrate used in the normal coordinate analysis (see Fig. 2 for atom numbering. Normalization constants are not given here; they are chosen as $N=\left(\sum c_{i}^{2}\right)^{-1 / 2}$, where $c_{\mathrm{i}}$ are the coefficients of the individual valence coordinates; $\nu$, bond stretching; $\delta$, bending; $\omega$, wagging; $\rho$, rocking; tw, twisting; $\tau$, torsion; as., asymmetric; s., symmetric)

\begin{tabular}{|c|c|c|c|}
\hline & Approximate description & Symmetry $^{\mathrm{a}}$ & Definition \\
\hline $\mathrm{S}_{1}$ & $\nu \mathrm{C}=\mathrm{O}$ & $\mathrm{A}^{\prime}$ & $\nu \mathrm{C}=\mathrm{O}$ \\
\hline $\mathrm{S}_{2}$ & $\nu \mathrm{C}-\mathrm{O}$ & $\mathrm{A}^{\prime}$ & $\nu \mathrm{C}-\mathrm{O}$ \\
\hline $\mathrm{S}_{3}$ & $\nu \mathrm{O}-\mathrm{C}\left(\mathrm{H}_{3}\right)$ & $\mathrm{A}^{\prime}$ & $\nu \mathrm{O}-\mathrm{C}\left(\mathrm{H}_{3}\right)$ \\
\hline $\mathrm{S}_{4}$ & $\nu \mathrm{C}-\mathrm{O}(\mathrm{H})$ & $\mathrm{A}^{\prime}$ & $\nu \mathrm{C}-\mathrm{O}(\mathrm{H})$ \\
\hline $\mathrm{S}_{5}$ & $\nu \mathrm{C}-\mathrm{C}$ & $\mathrm{A}^{\prime}$ & $\nu \mathrm{C}-\mathrm{C}$ \\
\hline $\mathrm{S}_{6}$ & $\nu \mathrm{CC} \mathrm{s}$ & $\mathrm{A}^{\prime}$ & $\nu \mathrm{CC}_{(7)}+\nu \mathrm{CC}_{(8)}$ \\
\hline $\mathrm{S}_{7}$ & $\nu \mathrm{OCH}_{3}$ as $^{\prime}$. & $\mathrm{A}^{\prime}$ & $2 \nu \mathrm{CH}_{(11)}-\nu \mathrm{CH}_{(10)}-\nu \mathrm{CH}_{(12)}$ \\
\hline $\mathrm{S}_{8}$ & $\nu \mathrm{OCH}_{3} \mathrm{~s}$ & $\mathrm{~A}^{\prime}$ & $\nu \mathrm{CH}_{(11)}+\nu \mathrm{CH}_{(10)}+\nu \mathrm{CH}_{(12)}$ \\
\hline $\mathrm{S}_{9}$ & $\nu \mathrm{O}-\mathrm{H}$ & $\mathrm{A}^{\prime}$ & $\nu \mathrm{O}-\mathrm{H}$ \\
\hline$S_{10}$ & $\nu \mathrm{CH}_{3}$ as $^{\prime}$. (1) & $\mathrm{A}^{\prime}$ & $2 \nu \mathrm{CH}_{(14)}-\nu \mathrm{CH}_{(13)}-\nu \mathrm{CH}_{(15)}+2 \nu \mathrm{CH}_{(17)}-\nu \mathrm{CH}_{(16)}-\nu \mathrm{CH}_{(18)}$ \\
\hline$S_{11}$ & $\nu \mathrm{CH}_{3}$ as $^{\prime}$. (2) & $\mathrm{A}^{\prime}$ & $\nu \mathrm{CH}_{(13)}-\nu \mathrm{CH}_{(15)}+\nu \mathrm{CH}_{(16)}-\nu \mathrm{CH}_{(18)}$ \\
\hline$S_{12}$ & $\nu \mathrm{CH}_{3} \mathrm{~s}^{\prime}$ & $\mathrm{A}^{\prime}$ & $\nu \mathrm{CH}_{(14)}+\nu \mathrm{CH}_{(13)}+\nu \mathrm{CH}_{(15)}+\nu \mathrm{CH}_{(17)}+\nu \mathrm{CH}_{(16)}+\nu \mathrm{CH}_{(18)}$ \\
\hline$S_{13}$ & $\delta \mathrm{O}=\mathrm{C}-\mathrm{O}$ & $\mathrm{A}^{\prime}$ & $2 \delta \mathrm{O}=\mathrm{C}-\mathrm{O}-\delta \mathrm{CC}=\mathrm{O}-\delta \mathrm{CCO}$ \\
\hline $\mathrm{S}_{14}$ & $\delta \mathrm{CC}=\mathrm{O}$ & $\mathrm{A}^{\prime}$ & $\delta \mathrm{CC}=\mathrm{O}-\delta \mathrm{CCO}$ \\
\hline$S_{15}$ & $\delta \mathrm{COC}$ & $\mathrm{A}^{\prime}$ & $\delta \mathrm{COC}$ \\
\hline$S_{16}$ & $\delta \mathrm{COH}$ & $\mathrm{A}^{\prime}$ & $\delta \mathrm{COH}$ \\
\hline$S_{17}$ & $\delta \mathrm{OCC}$ & $\mathrm{A}^{\prime}$ & $4 \delta \mathrm{OCC}-\delta \mathrm{CCC}_{(7)}-\delta \mathrm{CCC}_{(8)}-\delta \mathrm{OCC}_{(7)}-\delta \mathrm{OCC}_{(8)}$ \\
\hline $\mathrm{S}_{18}$ & $\delta \mathrm{C}\left(\mathrm{CH}_{3}\right)_{2}$ & $\mathrm{~A}^{\prime}$ & $5 \delta \mathrm{C}_{(7)} \mathrm{CC}_{(8)}-\delta \mathrm{OCC}-\delta \mathrm{CCC}_{(7)}-\delta \mathrm{CCC}_{(8)}-\delta \mathrm{OCC}_{(7)} \delta \mathrm{OCC}_{(8)}$ \\
\hline$S_{19}$ & $\omega \mathrm{C}\left(\mathrm{CH}_{3}\right)_{2}$ & $\mathrm{~A}^{\prime}$ & $\delta \mathrm{CCC}_{(7)}+\delta \mathrm{CCC}_{(8)}-\delta \mathrm{OCC}_{(7)}-\delta \mathrm{OCC}_{(8)}$ \\
\hline $\mathrm{S}_{20}$ & $\delta \mathrm{OCH}_{3}$ as.' & $\mathrm{A}^{\prime}$ & $2 \delta \mathrm{H}_{(10)} \mathrm{CH}_{(12)}-\delta \mathrm{H}_{(11)} \mathrm{CH}_{(10)}-\delta \mathrm{H}_{(11)} \mathrm{CH}_{(12)}$ \\
\hline$S_{21}$ & $\delta \mathrm{OCH}_{3} \mathrm{~s}$ & $\mathrm{~A}^{\prime}$ & $\delta \mathrm{H}_{(10)} \mathrm{CH}_{(12)}+\delta \mathrm{H}_{(11)} \mathrm{CH}_{(10)}+\delta \mathrm{H}_{(11)} \mathrm{CH}_{(12)}-\delta \mathrm{CCH}_{(12)}-\delta \mathrm{CCH}_{(10)}-\delta \mathrm{CCH}_{(12)}$ \\
\hline$S_{22}$ & $\delta \mathrm{CH}_{3}$ as.' (1) & $\mathrm{A}^{\prime}$ & $\begin{array}{l}2 \delta \mathrm{H}_{(13)} \mathrm{CH}_{(15)}-\delta \mathrm{H}_{(14)} \mathrm{CH}_{(13)}-\delta \mathrm{H}_{(14)} \mathrm{CH}_{(15)}+2 \delta \mathrm{H}_{(16)} \mathrm{CH}_{(18)}-\delta \mathrm{H}_{(17)} \mathrm{CH}_{(16)}- \\
\delta \mathrm{H}_{(17)} \mathrm{CH}_{(18)}\end{array}$ \\
\hline $\mathrm{S}_{23}$ & $\delta \mathrm{CH}_{3}$ as.' (2) & $\mathrm{A}^{\prime}$ & $\delta \mathrm{H}_{(14)} \mathrm{CH}_{(13)}-\delta \mathrm{H}_{(14)} \mathrm{CH}_{(15)}+\delta \mathrm{H}_{(17)} \mathrm{CH}_{(16)}-\delta \mathrm{H}_{(17)} \mathrm{CH}_{(18)}$ \\
\hline $\mathrm{S}_{24}$ & $\delta \mathrm{CH}_{3} \mathrm{~s} .^{\prime}$ & $\mathrm{A}^{\prime}$ & $\begin{array}{l}\delta \mathrm{H}_{(13)} \mathrm{CH}_{(15)}+\delta \mathrm{H}_{(14)} \mathrm{CH}_{(13)}+\delta \mathrm{H}_{(14)} \mathrm{CH}_{(15)}-\delta \mathrm{CCH}_{(13)}-\delta \mathrm{CCH}_{(14)}-\delta \mathrm{CCH}_{(15)}+ \\
\delta \mathrm{H}_{(16)} \mathrm{CH}_{(18)}+\delta \mathrm{H}_{(17)} \mathrm{CH}_{(16)}+\delta \mathrm{H}_{(17)} \mathrm{CH}_{(18)}-\delta \mathrm{CCH}_{(16)}-\delta \mathrm{CCH}_{(17)}-\delta \mathrm{CCH}_{(18)}\end{array}$ \\
\hline $\mathrm{S}_{25}$ & $\rho \mathrm{OCH}_{3}{ }^{\prime}$ & $\mathrm{A}^{\prime}$ & $2 \delta \mathrm{CCH}_{(12)}-\delta \mathrm{CCH}_{(10)}-\delta \mathrm{CCH}_{(12)}$ \\
\hline$S_{26}$ & $\rho \mathrm{CH}_{3}{ }^{\prime}(1)$ & $\mathrm{A}^{\prime}$ & $2 \delta \mathrm{CCH}_{(14)}-\delta \mathrm{CCH}_{(13)}-\delta \mathrm{CCH}_{(15)}+2 \delta \mathrm{CCH}_{(17)}-\delta \mathrm{CCH}_{(16)}-\delta \mathrm{CCH}_{(18)}$ \\
\hline $\mathrm{S}_{27}$ & $\rho \mathrm{CH}_{3}{ }^{\prime}(2)$ & $\mathrm{A}^{\prime}$ & $\delta \mathrm{CCH}_{(13)}-\delta \mathrm{CCH}_{(15)}+\delta \mathrm{CCH}_{(16)}-\delta \mathrm{CCH}_{(18)}$ \\
\hline $\mathrm{S}_{28}$ & $\tau \mathrm{CC}$ s. & $\mathrm{A}^{\prime}$ & $\tau \mathrm{C}-\mathrm{C}_{(7)}+\tau \mathrm{C}-\mathrm{C}_{(8)}$ \\
\hline$S_{29}$ & $\nu \mathrm{CC}$ as. & $A^{\prime \prime}$ & $\nu \mathrm{CC}_{(7)}-\nu \mathrm{CC}_{(8)}$ \\
\hline $\mathrm{S}_{30}$ & $\nu \mathrm{OCH}_{3}$ as." & $A^{\prime \prime}$ & $\nu \mathrm{CH}_{(10)}-\nu \mathrm{CH}_{(12)}$ \\
\hline$S_{31}$ & $\nu \mathrm{CH}_{3}$ as." (1) & $\mathrm{A}^{\prime \prime}$ & $2 \nu \mathrm{CH}_{(14)}-\nu \mathrm{CH}_{(13)}-\nu \mathrm{CH}_{(15)}-2 \nu \mathrm{CH}_{(17)}+\nu \mathrm{CH}_{(16)}+\nu \mathrm{CH}_{(18)}$ \\
\hline$S_{32}$ & $\nu \mathrm{CH}_{3}$ as." (2) & $A^{\prime \prime}$ & $\nu \mathrm{CH}_{(13)}-\nu \mathrm{CH}_{(15)}-\nu \mathrm{CH}_{(16)}+\nu \mathrm{CH}_{(18)}$ \\
\hline$S_{33}$ & $\nu \mathrm{CH}_{3} \mathrm{~s} . "$ & $\mathrm{~A}^{\prime \prime}$ & $\nu \mathrm{CH}_{(14)}+\nu \mathrm{CH}_{(13)}+\nu \mathrm{CH}_{(15)}-\nu \mathrm{CH}_{(17)-} \nu \mathrm{CH}_{(16)}-\nu \mathrm{CH}_{(18)}$ \\
\hline $\mathrm{S}_{34}$ & $\mathrm{TwC}\left(\mathrm{CH}_{3}\right)_{2}$ & $\mathrm{~A}^{\prime \prime}$ & $\delta \mathrm{CCC}_{(7)}-\delta \mathrm{CCC}_{(8)}-\delta \mathrm{OCC}_{(7)}+\delta \mathrm{OCC}_{(8)}$ \\
\hline $\mathrm{S}_{35}$ & $\rho \mathrm{C}\left(\mathrm{CH}_{3}\right)_{2}$ & $\mathrm{~A}^{\prime \prime}$ & $\delta \mathrm{CCC}_{(7)}-\delta \mathrm{CCC}_{(8)}+\delta \mathrm{OCC}_{(7)}-\delta \mathrm{OCC}_{(8)}$ \\
\hline$S_{36}$ & $\delta \mathrm{OCH}_{3}$ as." & $A^{\prime \prime}$ & $\delta \mathrm{H}_{(11)} \mathrm{CH}_{(10)}-\delta \mathrm{H}_{(11)} \mathrm{CH}_{(12)}$ \\
\hline$S_{37}$ & $\delta \mathrm{CH}_{3}$ as." (1) & $\mathrm{A}^{\prime \prime}$ & $\begin{array}{l}2 \delta \mathrm{H}_{(13)} \mathrm{CH}_{(15)}-\delta \mathrm{H}_{(14)} \mathrm{CH}_{(13)}-\delta \mathrm{H}_{(14)} \mathrm{CH}_{(15)}-2 \delta \mathrm{H}_{(16)} \mathrm{CH}_{(18)}+\delta \mathrm{H}_{(17)} \mathrm{CH}_{(16)}+ \\
\delta \mathrm{H}_{(17)} \mathrm{CH}_{(18)}\end{array}$ \\
\hline $\mathrm{S}_{38}$ & $\delta \mathrm{CH}_{3}$ as." (2) & $\mathrm{A}^{\prime \prime}$ & $\delta \mathrm{H}_{(14)} \mathrm{CH}_{(13)}-\delta \mathrm{H}_{(14)} \mathrm{CH}_{(15)}-\delta \mathrm{H}_{(17)} \mathrm{CH}_{(16)}+\delta \mathrm{H}_{(17)} \mathrm{CH}_{(18)}$ \\
\hline $\mathrm{S}_{39}$ & $\delta \mathrm{CH}_{3}$ s." & $\mathrm{A}^{\prime \prime}$ & $\begin{array}{l}\delta \mathrm{H}_{(13)} \mathrm{CH}_{(15)}+\delta \mathrm{H}_{(14)} \mathrm{CH}_{(13)}+\delta \mathrm{H}_{(14)} \mathrm{CH}_{(15)}-\delta \mathrm{CCH}_{(13)}-\delta \mathrm{CCH}_{(14)}-\delta \mathrm{CCH}_{(15)}- \\
\delta \mathrm{H}_{(16)} \mathrm{CH}_{(18)}-\delta \mathrm{H}_{(17)} \mathrm{CH}_{(16)}-\delta \mathrm{H}_{(17)} \mathrm{CH}_{(18)}+\delta \mathrm{CCH}_{(16)}+\delta \mathrm{CCH}_{(17)}+\delta \mathrm{CCH}_{(18)}\end{array}$ \\
\hline $\mathrm{S}_{40}$ & $\rho \mathrm{OCH}_{3}^{\prime \prime}$ & $A^{\prime \prime}$ & $\delta \mathrm{CCH}_{(10)}-\delta \mathrm{CCH}_{(12)}$ \\
\hline $\mathrm{S}_{41}$ & $\rho \mathrm{CH}_{3}{ }^{\prime \prime}(1)$ & $\mathrm{A}^{\prime \prime}$ & $2 \delta \mathrm{CCH}_{(14)}-\delta \mathrm{CCH}_{(13)}-\delta \mathrm{CCH}_{(15)}-2 \delta \mathrm{CCH}_{(17)}+\delta \mathrm{CCH}_{(16)}+\delta \mathrm{CCH}_{(18)}$ \\
\hline $\mathrm{S}_{42}$ & $\rho \mathrm{CH}_{3}{ }^{\prime \prime}(2)$ & $\mathrm{A}^{\prime \prime}$ & $\delta \mathrm{CCH}_{(13)}-\delta \mathrm{CCH}_{(15)}-\delta \mathrm{CCH}_{(16)}+\delta \mathrm{CCH}_{(18)}$ \\
\hline $\mathrm{S}_{43}$ & $\rho \mathrm{C}=\mathrm{O}$ & $A^{\prime \prime}$ & $\rho \mathrm{C}=\mathrm{O}$ \\
\hline $\mathrm{S}_{44}$ & $\tau \mathrm{C}-\mathrm{O}$ & $\mathrm{A}^{\prime \prime}$ & $\tau \mathrm{C}-\mathrm{O}$ \\
\hline$S_{45}$ & $\tau \mathrm{C}-\mathrm{C}$ & $\mathrm{A}^{\prime \prime}$ & $\tau \mathrm{C}-\mathrm{C}$ \\
\hline $\mathrm{S}_{46}$ & $\tau \mathrm{C}-\mathrm{O}(\mathrm{H})$ & $A^{\prime \prime}$ & $\tau \mathrm{C}-\mathrm{O}(\mathrm{H})$ \\
\hline
\end{tabular}


Table 5 (continued)

\begin{tabular}{llll}
\hline & Approximate description & Symmetry $^{\mathrm{a}}$ & Definition \\
\hline $\mathrm{S}_{47}$ & $\tau \mathrm{O}-\mathrm{C}\left(\mathrm{H}_{3}\right)$ & $\mathrm{A}^{\prime \prime}$ & $\tau \mathrm{O}-\mathrm{C}\left(\mathrm{H}_{3}\right)$ \\
$\mathrm{S}_{48}$ & $\tau \mathrm{CC}$ as. & $\mathrm{A}^{\prime \prime}$ & $\tau \mathrm{C}-\mathrm{C}_{(7)}-\tau \mathrm{C}-\mathrm{C}_{(8)}$ \\
\hline
\end{tabular}

${ }^{\mathrm{a}}$ Symmetry species of the coordinate in the conformer belonging to the $\mathrm{C}_{\mathrm{s}}$ point group (Ss).

phase value (i.e. $3.7 \mathrm{~kJ} \mathrm{~mol}^{-1}$, compared with $9.5 \mathrm{~kJ} \mathrm{~mol}^{-1}$ in the gas phase).

Intermolecular hydrogen bonding in the liquid is certainly the main factor responsible for the stabilization of the Gsk conformer relatively to the Ss form. In fact, since the intramolecular hydrogen bond in Gsk is much weaker than in $\mathbf{S s}$, this conformer can establish stronger intermolecular hydrogen bonds to form associates in the liquid phase. In any case, it is worth mentioning that the Ss conformer, whose main stabilizing factor is the $\mathrm{OH} \cdots \mathrm{O}=$ intramolecular hydrogen bond, still has a high population in the liquid phase, further reinforcing the idea that this interaction is particularly strong, as already pointed out before.

\subsubsection{Methyl $\alpha$-hydroxy isobutyrate}

This molecule has 48 fundamental vibrations, spaning the irreducible representations $28 \mathrm{~A}^{\prime}+$
$20 \mathrm{~A}^{\prime \prime}$ in the most stable Ss conformer $\left(\mathrm{C}_{\mathrm{s}}\right.$ point group). Thus, all modes are active in both infrared and Raman. The definition of the symmetry coordinates used in the vibrational calculations is shown in Table 5 and the vibrational data summarized in Table 6. Spectra are presented in Figs. 6-8.

As for methyl glycolate, the calculated and experimental (MIS) vibrational data agree fairly well both with respect to frequencies and relative intensities. As expected, on the basis of the calculated relative energies of the various conformational states of this molecule, the spectra reveal the presence of two conformers (Ss and Gsk). The energy difference between these two conformers in the gaseous phase, at the temperature of the pre-mixture used to prepare the matrix $(298 \mathrm{~K})$, estimated from the experimental infrared intensities of the $\nu \mathrm{CC}$ s. bands ascribed to each one of the conformers (Ss: $789 \mathrm{~cm}^{-1}$; Gsk: $805 \mathrm{~cm}^{-1}$ ) amounts to $4.5 \mathrm{~kJ} \mathrm{~mol}^{-1}$, a slightly lower

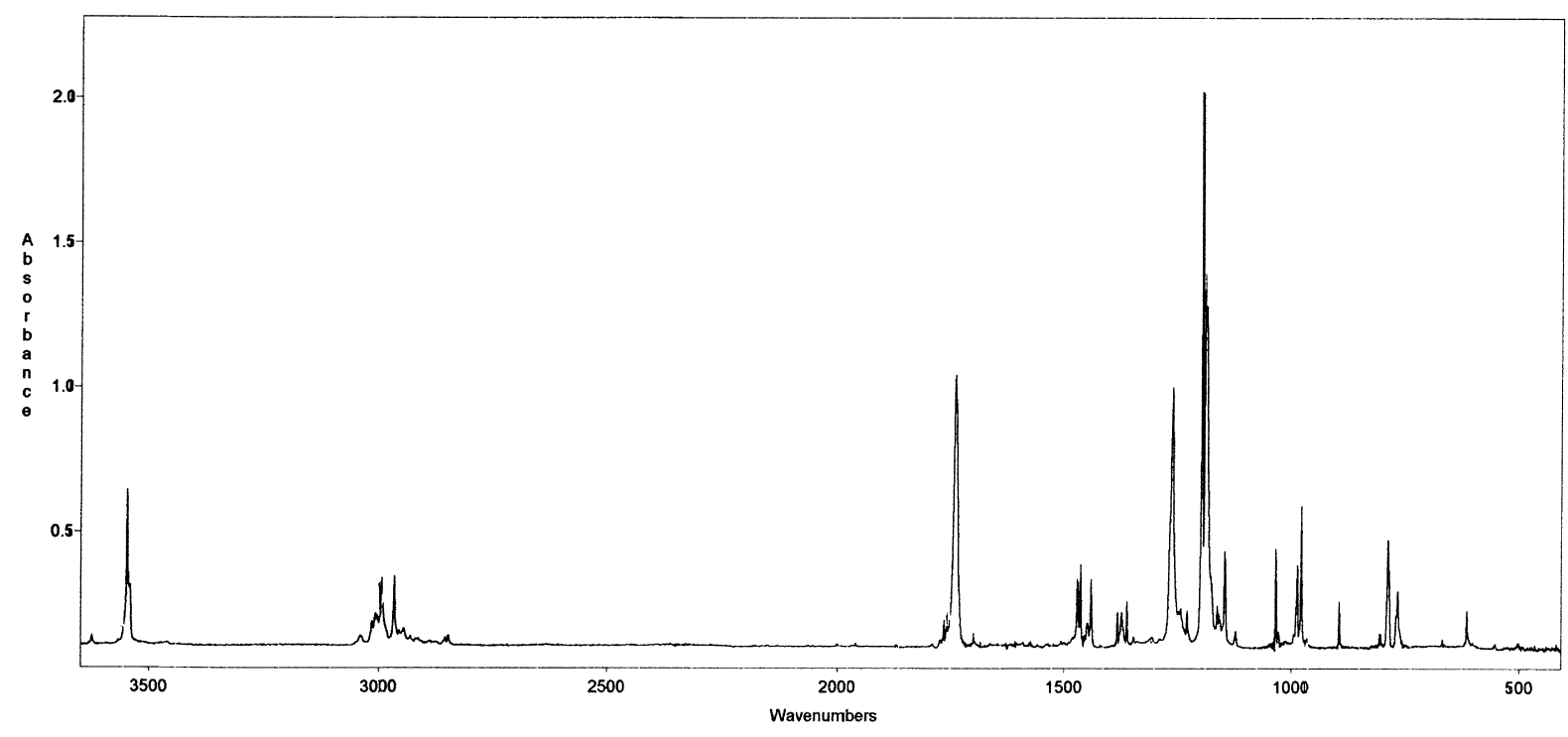

Fig. 6. MIS infrared spectrum of methyl $\alpha$-hydroxy isobutyrate in a argon matrix (M/S ratio $\approx 1000 ; T=17 \mathrm{~K}$ ). 
Table 6

Calculated (6-31G*) and experimental vibrational spectra of methyl $\alpha$-hydroxyisobutyrate and potential energy distribution (PED) (wavenumbers in $\mathrm{cm}^{-1} ; \nu$, stretching; $\delta$, bending; $\omega$, wagging; tw, twisting; $\rho$, rocking; $\tau$, torsion, s., symmetric; as., asymmetric)

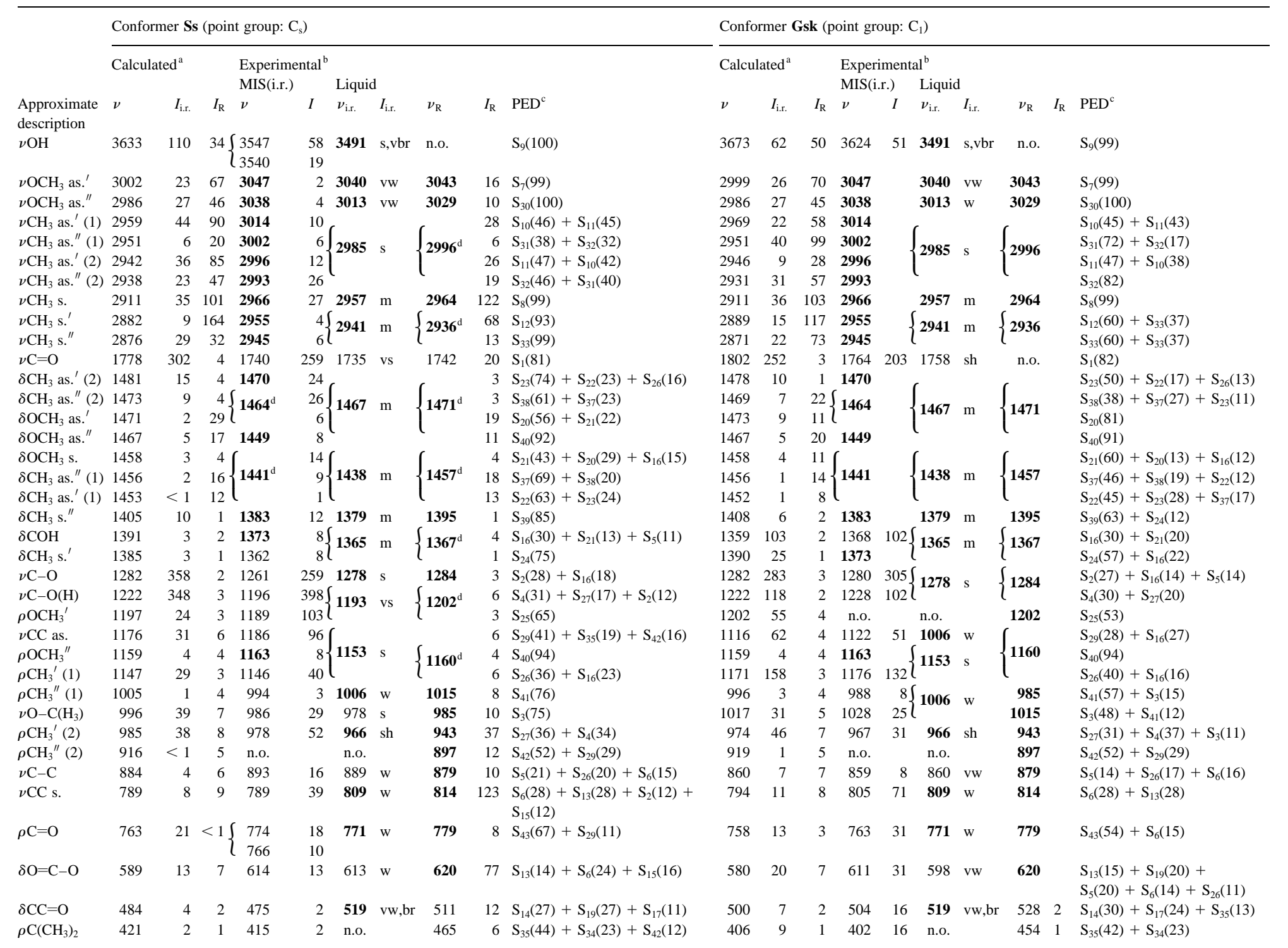




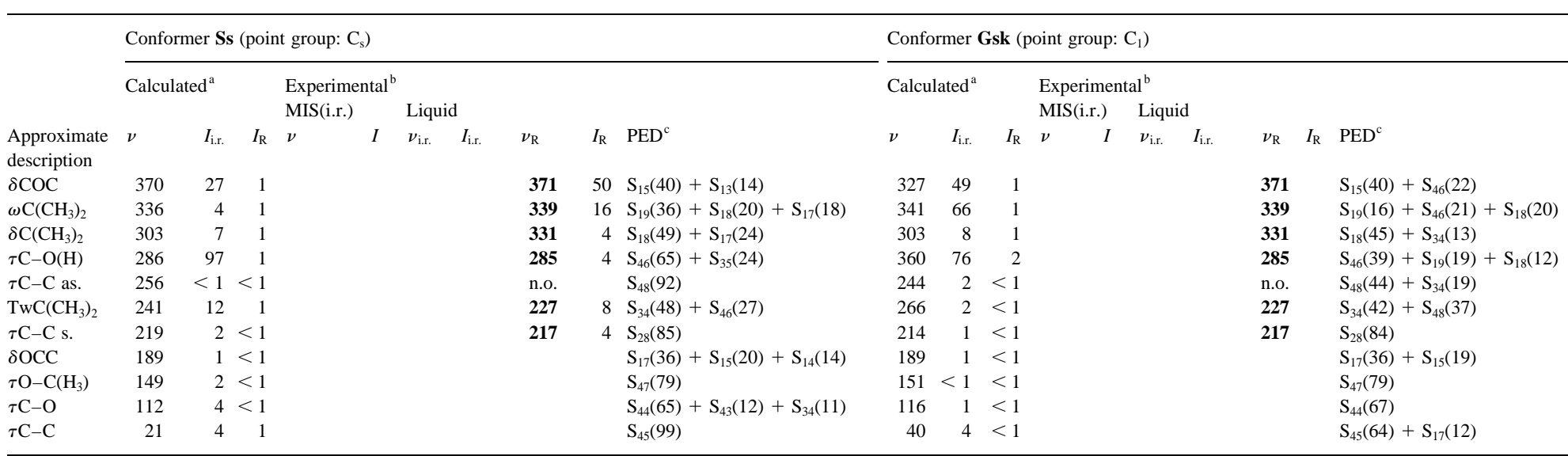

${ }^{\text {a }}$ Calculated i.r. intensities in $\mathrm{km} \mathrm{mol}^{-1}$; calculated Raman activities in a.m.u. $\AA^{2}$

${ }^{\mathrm{b}}$ Wavenumber values shown in bold represent bands considering to have contributions from both conformers; MIS intensities were normalized to the total calculated intensities of the bands which have an experimental counterpart by using the formula $I_{(i)}=I_{(i)}^{\mathrm{obs}} \times \Sigma_{j}=1, n I_{(j)}^{\mathrm{obs}} / \Sigma_{j}=1, n I_{(j)}^{\mathrm{calc}}$, where the sums extend to all bands observed (the intensity of the bands ascribed to both conformers is here assumed to be due only to the most stable form, since the expected contribution to these bands due to the higher energy conformer is small); A similar procedure was adopted in the case of the experimental Raman activities; liquid phase i.r. intensities were shown in a qualitative way using the usual notation.

${ }^{\mathrm{c}}$ See Table 5 for definition of symmetry coordinates; only PED values greater than 10 are shown.

${ }^{\mathrm{d}}$ Experimental intensities of the component bands were estimated by dividing the total observed intensity in consonance with their calculated intensity ratios. 


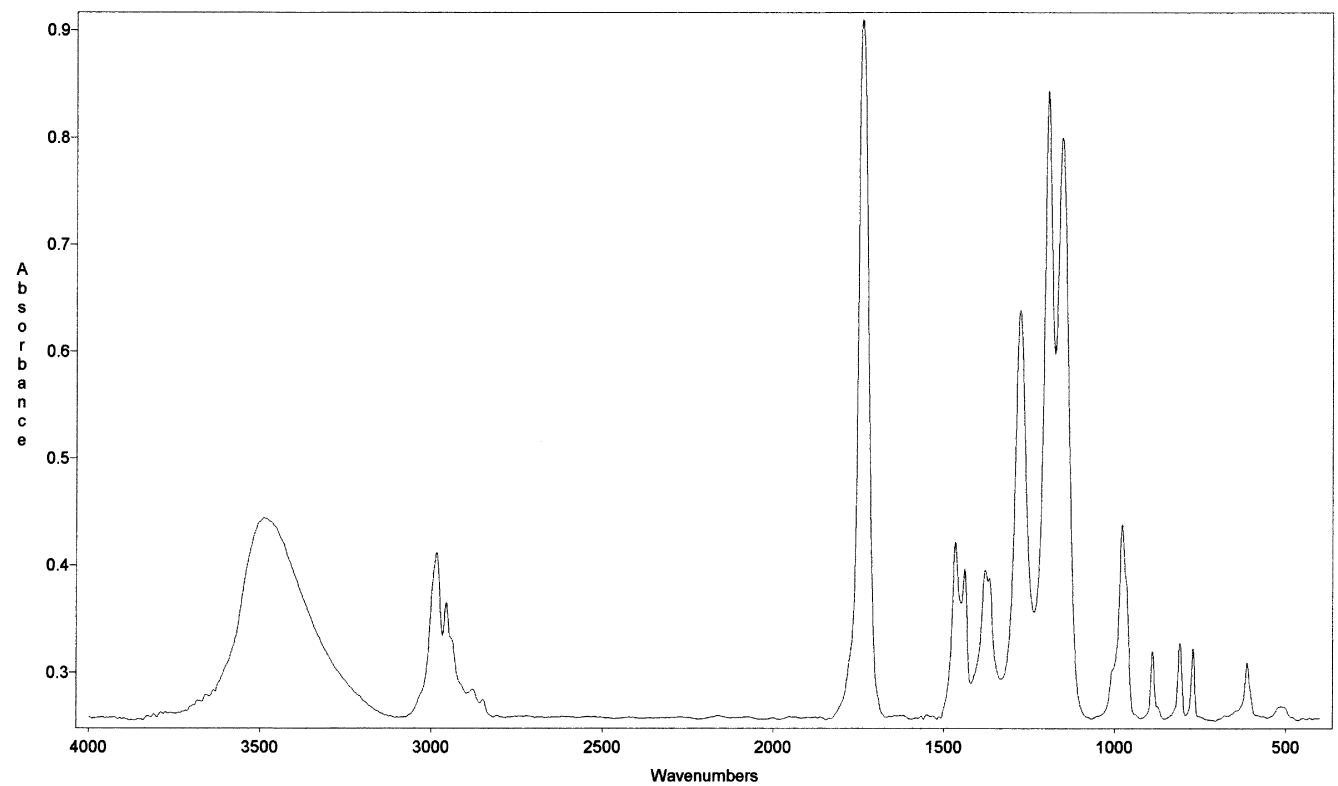

Fig. 7. Liquid phase infrared spectrum of methyl $\alpha$-hydroxy isobutyrate at room temperature.

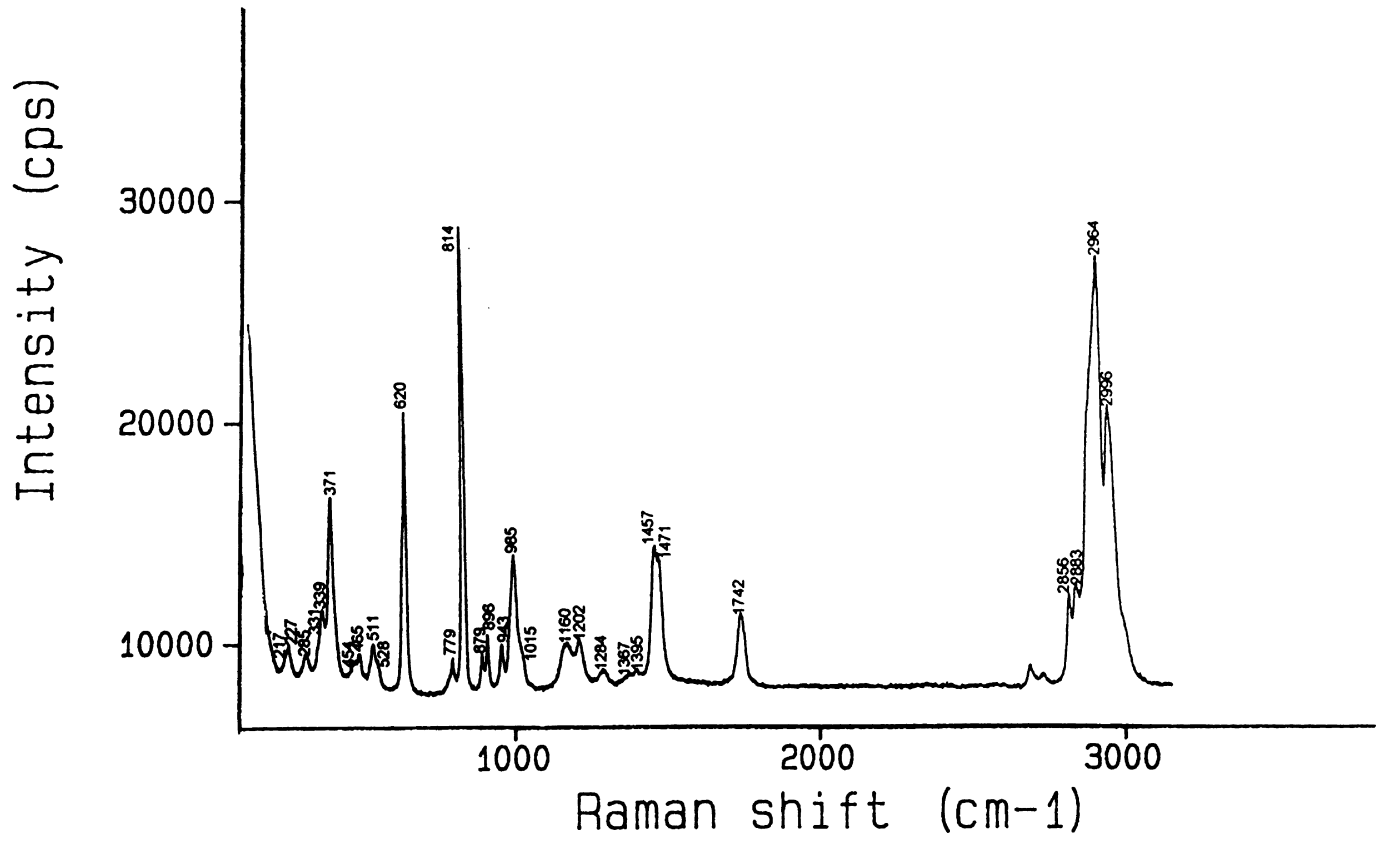

Fig. 8. Liquid phase Raman spectrum of methyl $\alpha$-hydroxy isobutyrate at room temperature. 
value than the $6-31 \mathrm{G}^{*}$ predicted value $\left(6.6 \mathrm{~kJ} \mathrm{~mol}^{-1}\right)$. In the liquid, this energy difference reduces to $3.4 \mathrm{~kJ} \mathrm{~mol}^{-1}$ (value estimated from the pair of Raman bands at 465 and $454 \mathrm{~cm}^{-1}$ ), a similar value to that obtained for methyl glycolate. The smaller relative stabilization of the Gsk form relative to the most stable form upon going from the gas phase to the pure liquid in methyl $\alpha$-hydroxy isobutyrate is consistent with both the presence in the $\mathbf{S s}$ form of this molecule of a weaker intramolecular hydrogen bond than in the analogous conformer of methyl glycolate and the expected smaller ability of the $\mathrm{OH}$ substituent of methyl $\alpha$-hydroxy isobutyrate to establish intermolecular hydrogen bonds due to the less acidic character of its hydroxylic hydrogen.

\section{Acknowledgements}

This work has been held within the PRAXIS XXI (QUI/2/2.1/412/94) research programme that is also partially funded by FEDER.

\section{References}

[1] E.V. Scott, J. Am. Acad. Derm. 11 (1984) 867.

[2] Y. Guzel, J. Mol. Struct. (Theochem) 366 (1996) 131.

[3] L. Moy, H. Murad, R.L. Moy, J. Derm. Surg. Oncol. 19 (1993) 243.

[4] E.V. Scott, Can. J. Derm. 43 (1989) 222.

[5] D.J. Mooney, Proceedings of the 15th Southern Biomedical Engineering Conference, New York, 1996.

[6] N.L. Allinger, M.P. Cava, D.C. de Jongh, C.R. Johnson, N.A. Lebel, C.L. Stevens, in: Guanabara (Ed.), Química Orgânica, 1978 and references therein.

[7] S. Krimm, C.Y. Liang, G.B.B.M. Sutherland, J. Chem. Phys. 17 (1949) 901.

[8] A.V. Stuart, G.B.B.M. Sutherland, J. Chem. Phys. 24 (1956) 559.
[9] R.D. Ellison, C.K. Johnson, H.A. Levy, Acta Cryst. B37 (1971) 333

[10] C.E. Blom, A. Bauder, J. Am. Chem. Soc. 104 (1982) 2993.

[11] H. Hasegawa, O. Ohashi, I. Yamaguchi, J. Mol. Struct. 82 (1982) 205.

[12] H. Hollenstein, T.K. Ha, Hs.H. Günther, J. Mol. Struct. 146 (1986) 289.

[13] G. Cassanas, M. Morssli, E. Fabrégue, L. Bardet, J. Raman Spectrosc. 22 (1991) 11.

[14] K. Iijima, M. Kato, B. Beagley, J. Mol. Struct. 295 (1993) 289.

[15] S. Jarmelo, R. Fausto, G. Maes, to be published.

[16] H. Hollenstein, R.W. Schar, N. Schwizgebel, G. Grassi, Hs.H. Günthard, Spectrochim. Acta 39 (1983) 193.

[17] H. Hollenstein, Hs.H. Günthard, J. Mol. Spectrosc. 84 (1980) 457.

[18] W.J. Hehre, R. Ditchefield, J.A. Pople, J. Chem. Phys. 56 (1972) 2257.

[19] M.J. Frisch, G.W. Trucks, H.B. Schlegel, P.M.W. Gill, B.G. Johson, M.A. Robb, J.R. Cheeseman, T. Keith, G.A. Petersen, J.A. Montgomery, K. Raghavachari, M.A. Al-Laham, V.G. Zakrzewski, J.V. Ortiz, J.B. Foresman, J. Cioslowski, B.B. Stefanov, A. Nanayakkara, M. Challacombe, C.Y. Peng, P.Y. Ayala, W. Chen, M.W. Wong, J.L. Andres, E.S. Replogle, R. Gomperts, R.L. Martin, D.J. Fox, J.S. Binkley, D.J. Defrees, J. Baker, J.P. Stewart, M. Head-Gordon, C. Gonzalez, J.A. Pople, Gaussian 94 (Revision E.2), Gaussian Inc., Pittsburgh, PA, 1994.

[20] H.B. Schlegel, PhD thesis, Queen's University, Kingston, Ontario, Canada, 1975.

[21] R. Fausto, TRANSFORMER (version 2.0), Departamento de Química, Universidade de Coimbra, Portugal, 1996.

[22] M.D.G. Faria, R. Fausto, BUILD-G and VIBRAT (version 2.0), Departamento de Química, Universidade de Coimbra, Portugal, 1996.

[23] R. Fausto, J.J.C. Teixeira-Dias, J. Mol. Struct. (Theochem) 150 (1987) 381.

[24] M.D.G. Faria, J.J.C. Teixeira-Dias, R. Fausto, Vibrat. Spectrosc. 2 (1991) 107.

[25] M.D.G. Faria, J.J.C. Teixeira-Dias, R. Fausto, J. Raman Spectrosc. 22 (1991) 519.

[26] M.D.G. Faria, J.J.C. Teixeira-Dias, R. Fausto, Vibrat. Spectrosc. 2 (1991) 43.

[27] J.J.C. Teixeira-Dias, R. Fausto, L.A.E. Batista, de Carvalho, J. Comput. Chem. 12 (1991) 1047.

[28] J.M.F. Neta, R. Fausto, J. Mol. Struct. 443 (1998) 41. 